SANDIA REPORT

SAND97-0312 • UC-400

Unlimited Release

Printed February 1997

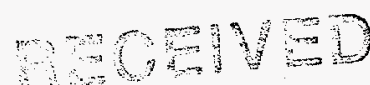

6193907

$0 S T$

\title{
Synchronization of Multiple Magnetically Switched Modules to Power Linear Induction Adder Accelerators
}

K. W. Reed, P. D. Kiekel

Prepared by

Sandia National Laboratories

Albuquerque, New Mexico 87185 and Livermore, California 94550

Sandia is a multiprogram laboratory operated by Sandia

Corporation, a Lockheed Martin Company for the United States

Department of Energy under Contract DE ACO4-94AL85000.

Approved for public release; distribution is unlimited

Whot

\section{1i Sandia National Laboratories}
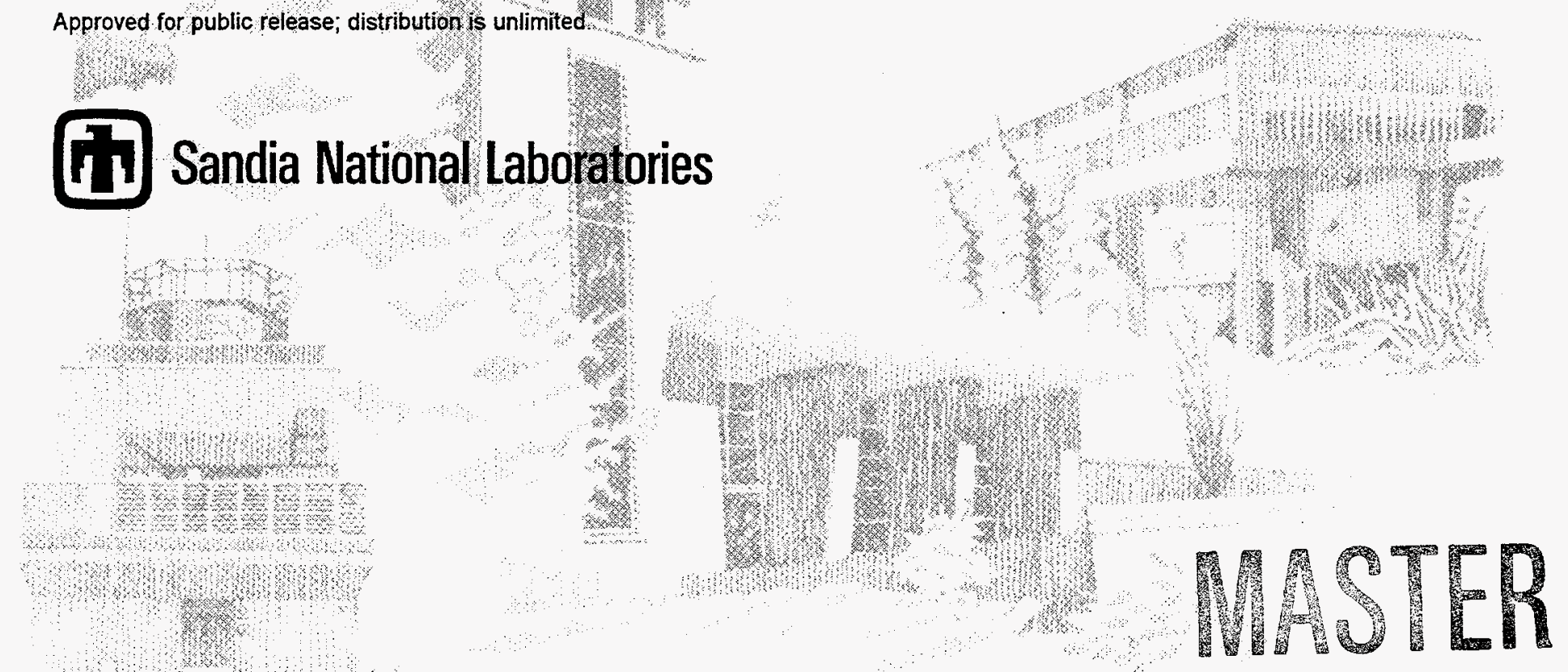
Issued by Sandia National Laboratories, operated for the United States Department of Energy by Sandia Corporation.

NOTICE: This report was prepared as an account of work sponsored by an agency of the United States Government. Neither the United States Government nor any agency thereof, nor any of their employees, nor any of their contractors, subcontractors, or their employees, makes any warranty, express or implied, or assumes any legal liability or responsibility for the accuracy, completeness, or usefulness of any information, apparatus, product, or process disclosed, or represents that its use would not infringe privately owned rights. Reference herein to any specific commercial product, process, or service by trade name, trademark, manufacturer, or otherwise, does not necessarily constitute or imply its endorsement, recommendation, or favoring by the United States Government, any agency thereof, or any of their contractors or subcontractors. The views and opinions expressed herein do not necessarily state or reflect those of the United States Government, any agency thereof, or any of their contractors.

Printed in the United States of America. This report has been reproduced directly from the best available copy.

Available to DOE and DOE contractors from

Office of Scientific and Technical Information

P.O. Box 62

Oak Ridge, TN 37831

Prices available from (615) 576-8401, FTS 626-8401

Available to the public from

National Technical Information Service

U.S. Department of Commerce

5285 Port Royal Rd

Springfield, VA 22161

NTIS price codes

Printed copy: $\mathrm{A03}$

Microfiche copy: A01 
SAND97-0312

Uniimited Release

Printed February 1997
Distribution

Category UC-400

\title{
Synchronization of Multiple Magnetically Switched Modules to Power Linear Induction Adder Accelerators
}

\author{
K. W. Reed \& P. D. Kiekel \\ Repetitive \& Innovative Pulsed Power Technology \\ Organization 9543 \\ Sandia National Laboratories \\ P. O. Box 5800 \\ Albuquerque NM 87185-1152
}

\begin{abstract}
In applications where multiple magnetic modulators are used to drive a single Linear Induction Voltage Adder (LIVA) or Linear Accelerator (LINAC), it is essential that the outputs of the modulators be synchronized. Output rise times are typically in the $10 \mathrm{~ns}$ to $20 \mathrm{~ns}$ range, often making it necessary to synchronize to within less than 1ns. Microprocessor and electronic feedback schemes have been developed and demonstrated ${ }^{1-6}$ that achieve the required level of synchronization, however, they are sophisticated and potentially complex. In a quest for simplicity, this work seeks to determine the achievable level of modulator to modulator timing jitter that can be obtained with simple design practices and passive techniques. Sources of output pulse time jitter in magnetic modulators are reviewed and some basic modulator design principles that can be used to minimize the intrinsic time jitter between modulators are discussed. A novel technique for passive synchronization is presented.
\end{abstract}




\section{Acknowledgment}

The authors thank Jacob Adcock, Jimmy J. Flores, Michael J. Harden Leonard E. Martinez, Gary E. Peña, Larry X. Schneider, Gerard A. Torres, and Gerry J. Weber for their ideas and technical inputs and for working with us to assemble the Dos Lineas facility and prepare it for the experimental measurements.

This work was supported by the United States Department of Energy under contract DE-AC0494ACAC85000. 


\section{DISCLAMMER}

Portions of this document may be illegible in electronic image products. Images are produced from the best available original document. 


\section{Contents}

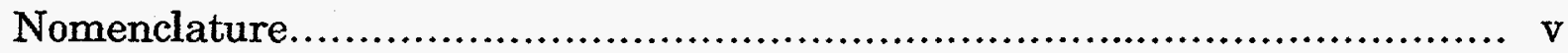

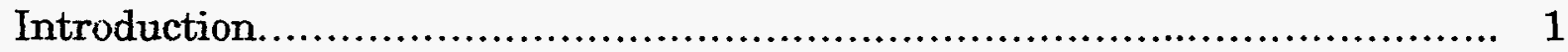

Characterization of Jitter....................................................... 1

Sources of Timing Jitter in Magnetic Switches..................................... 2

Dos Lineas Modulator Pair............................................................. 4

Reasonable Design Techniques...................................................... 6

Results of Dos Lineas Experiments............................................... 8

Synchronization by Magnetic Coupling........................................... 10

PSPICE Simulations............................................................... 11

Demonstration of Magnetic Coupling.......................................... 11

Effect of Magnetic Coupling on Uncoupled Down-Stream Switches............. 18

Conclusions................................................................... 20

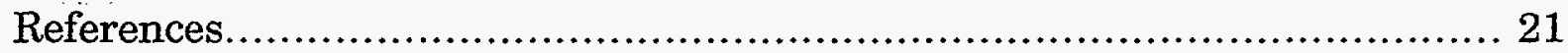

\section{List of Figures}

Figure 1 Circuit for each half of the Dos Lineas magnetic modulator pair. 4 The two modulators are respectively designated " $\mathrm{A}$ " and " $\mathrm{B}$ ".

Figure 2 Dos Lineas Modulator Pair 5

$\begin{array}{llll}\text { Figure } 3 & \text { Typical Dos Lineas magnetic switch (MS2). Large outside } & 7\end{array}$ windings are the coupling windings, main windings are barely visible inside the cooling manifold.

Figure 4 Comparison of voltage ripple on $\mathrm{C} 1$ with $0.38 \times$ tout indicates that the output timing jitter is mainly due to ripple on the initial charge voltage.

Figure 5 Measured output time-shift on modulator "A" relative to trigger pulse. Inset is detail of shots 70 through 100 .

Figure 6 The Magnetic Coupling Technique

Figure $7 \quad$ PSPICE simulation of two stage magnetic modulator pair. Modulator " $\mathrm{A}$ " switches have $2 \%$ more packing factor than modulator "B" switches: (a) without magnetic coupling, (b) with magnetic coupling.

Figure 8 PSPICE simulation of two stage magnetic modulator pair. Modulator " $\mathrm{A}$ " is charged $7 \%$ higher than modulator " $\mathrm{B}$ ": (a) without magnetic coupling, (b) with magnetic coupling. 
Figure 9 PSPICE simulation of two stage magnetic modulator pair. Modulator " $\mathrm{A}$ " is triggered $1 \mu \mathrm{s}$ after: modulator " $\mathrm{B}$ ":

(a) without magnetic coupling, (b) with magnetic coupling.

Figure 10 Dos Lineas circuit with magnetic coupling between MS2A \&

MS2B and between MS3A \& MS3B

Figure 11 Effect of magnetic coupling on transient and on random jitter other, between Dos Lineas outputs. Inset shows expanded view of shots 50-100. (Uncoupled data was shifted up in inset)

Figure 12 Output time shift between modulator " $A$ " and " $B$ " with modulator " $\mathrm{A}$ " triggered $1 \mu \mathrm{s}$ before modulator " $\mathrm{B}$ ".

Figure 13 Output time shift between modulator " $A$ " and " $B$ " with modulator " $\mathrm{A}$ " charged 324 volts higher then modulator " $\mathrm{B}$ ".

Figure 14 Output time shift between modulator "A" and "B" with MS2A \& 19 $B$ coupled and MS3A \& B not coupled as a function of input trigger timing offset

Figure 15 Output time shift on modulator "B" as a function of bias on MS3A \& MS3B

\section{List of Tables}

Table 1 Measurements of magnetic switch jitter (MS4 / MS7).

Table 2 Steady-State timing jitter for shots 70 through 99 for various cases. 8 


\section{Nomenclature}

C0

$\mathrm{COA}$

$\mathrm{COB}$

C1

C1A

C1B

$\mathrm{C} 2$

$\mathrm{C} 2 \mathrm{~A}$

C2B

C3

C3A

C3B

$\mathrm{C} 4$

C4A

C4B

LINAC

LIVA

MS2

MS2A

MS2B

MS3

MS3A

MS3B

MS4

MS4A

MS4B

MS7

PF

PFL

SCR1

SCR1A

SCR1B

SCR2

SCR2A

SCR2B

VC1

VC1A

VC1B

VC2

$\mathrm{VC2A}$

$\mathrm{VC} 2 \mathrm{~B}$

VC3

VC3A capacitor zero in the modulator capacitor zero in the " $\mathrm{A}$ " modulator capacitor zero in the " $\mathrm{B}$ " modulator capacitor one in the modulator capacitor one in the " $A$ " modulator capacitor one in the " $\mathrm{B}$ " modulator capacitor two in the modulator capacitor two in the " $\mathrm{A}$ " modulator capacitor two in the " $\mathrm{B}$ " modulator capacitor three in the modulator capacitor three in the " $\mathrm{A}$ " modulator capacitor three in the " $\mathrm{B}$ " modulator capacitor four in the modulator capacitor four in the " $\mathrm{A}$ " modulator capacitor four in the " $\mathrm{B}$ " modulator Linear Accelerator Linear Induction Voltage Adder magnetic switch two magnetic switch two in the "A" modulator magnetic switch two in the " $\mathrm{B}$ " modulator magnetic switch three magnetic switch three in the " $\mathrm{A}$ " modulator magnetic switch three in the " $\mathrm{B}$ " modulator magnetic switch four magnetic switch four in the " $A$ " modulator magnetic switch four in the " $\mathrm{B}$ " modulator magnetic switch seven in the RHEPP II modulator packing factor

pulse forming line silicon controlled rectifier one silicon controlled rectifier one in the " $\mathrm{A}$ " modulator silicon controlled rectifier one in the " $\mathrm{B}$ " modulator silicon controlled rectifier two silicon controlled rectifier two in the " $\mathrm{A}$ " modulator silicon controlled rectifier two in the " $\mathrm{B}$ " modulator voltage on capacitor one voltage on capacitor one in the " $\mathrm{A}$ " modulator voltage on capacitor one in the " $\mathrm{B}$ " modulator voltage on capacitor two voltage on capacitor two in the "A" modulator voltage on capacitor two in the "B" modulator voltage on capacitor three voltage on capacitor three in the " $A$ " modulator 


\section{Nomenclature (continued)}

VC3B

$\mathrm{VC4}$

$\mathrm{VC} 4 \mathrm{~A}$

$\mathrm{VC} 4 \mathrm{~B}$

Fidu

$\mathrm{kV}$

$\mathrm{kW}$

MW

$\mu F d$

$\mu \mathrm{Hy}$

us

$\mathrm{nFd}$

ns

$\Omega$

Std

B-H

$\mathrm{di} / \mathrm{dt}$

$\Delta \mathrm{t}_{\text {out }}$

magnetic switch

modulator

n

$\sigma$

$\tau$

$t_{\mathrm{sw}}$

$\mathrm{v} * \mathrm{t}$

volt-second product voltage on capacitor three in the " $\mathrm{B}$ " modulator voltage on capacitor four voltage on capacitor four in the "A" modulator voltage on capacitor four in the " $\mathrm{B}$ " modulator

fiducial

kilovolt $\quad\left(10^{3}\right.$ Volts $)$

kilowatt (103 Watts)

megawatt (106 Watts)

micro Farad (10 $10^{-6}$ Farads)

micro Henry ( $10^{-6}$ Henries)

micro second ( $10^{-6}$ seconds)

nano Farad (10 $10^{-9}$ Farads)

nano second $\left(10^{-9}\right.$ seconds $)$

Ohm

standard deviation

Magnetic Flux versus Magnetic Field Intensity time derivative of the current

time shift at the output of the modulator

a saturable magnetic core with electrical windings

a circuit consisting of a series of magnetic switches and capacitors that processes an initial charge into a pulse index for the $\mathrm{n}^{\text {th }}$ stage of a magnetic modulator standard deviation

time from initialization of charging to the peak voltage applied to a magnetic switch

time from initialization of charging to the point at which a magnetic switch closes

the integral of the voltage applied to a magnetic switch with respect to time

the integral of the voltage applied to a magnetic switch with respect to time 


\section{Synchronization of Multiple Magnetically Switched Modules to Power Linear Induction Adder Accelerators}

\section{Introduction}

A number of industrial applications requiring continuously operating pulse powered X-ray and electron beam generators necessitate power levels approaching $1 \mathrm{MW}$. Food irradiation to eliminate pathogens, waste water treatment applications, and hazardous waste treatment require accelerating potentials in the $5 \mathrm{MV}$ to $10 \mathrm{MV}$ range to maximize efficiency and treatment depth as well as high power levels to provide high throughput. Linear induction voltage addition allows the output voltage to be increased by simply adding more stages; however, the power required for this increased voltage necessitates multiple, parallel pulse forming and modulator networks. For example, the Repetitive High Energy Pulsed Power (RHEPP) modulator at Sandia drives a $2 \mathrm{MV}$ accelerator with an average output power of $300 \mathrm{~kW}$ from a single magnetic compressor and pulse forming line. Using the RHEPP technology to produce $5 \mathrm{MV}$ would require $700 \mathrm{~kW}$. Impedance constraints prohibit achieving these power levels from a single module. In order to combine the outputs of multiple pulsed power modules using a linear induction voltage adder (LIVA) or induction linear accelerator (LINAC), it is necessary to synchronize the outputs to within a fraction of the output rise time, which is typically ten's of nanoseconds.

\section{Characterization of Jitter}

The first objective of this work was to establish a reference for typical magnetic switch jitter. The timing and voltage jitter was measured on two of the magnetic switches in the RHEPP II machine while operating between 0 and $20 \mathrm{~Hz}$ rep-rate. There are seven stages of magnetic compression in the RHEPP II modulator, and each successive stage uses a progressively faster magnetic switch, MS1 through MS7. It was anticipated that the jitter introduced

Table 1. Measurements of magnetic switch jitter (MS4 / MS7).

\begin{tabular}{|c|c|c|c|c|}
\hline $\begin{array}{l}\text { Number of } \\
\text { Waveforms } \\
\text { Used } \\
\text { MS4 / MS7 }\end{array}$ & $\begin{array}{l}\text { Mean Charge } \\
\text { Voltage }[\mathrm{kV}]\end{array}$ & $\begin{array}{l}\text { Charge } \\
\text { Voltage } \\
\text { Std. Dev. } \\
\text { Percent of } \\
\text { Mean }\end{array}$ & $\begin{array}{l}\text { Mean Hold- } \\
\text { Off Time [ } \mu \mathrm{s}]\end{array}$ & $\begin{array}{l}\text { Hold Off } \\
\text { Time Std. } \\
\text { Dev. } \\
\text { Percent of } \\
\text { Mean }\end{array}$ \\
\hline $62 / 297$ & $237 / 380$ & $1.31 / 2.93$ & $16.1 / 0.173$ & $1.18 / 1.06$ \\
\hline $58 / 177$ & $271 / 458$ & $0.76 / 1.75$ & $15.4 / 0.173$ & $0.60 / 0.97$ \\
\hline $60 / 267$ & $273 / 465$ & $0.87 / 1.90$ & $15.4 / 0.172$ & $0.73 / 0.98$ \\
\hline $62 / 214$ & $274 / 464$ & $0.94 / 1.76$ & $15.4 / 0.172$ & $0.72 / 0.88$ \\
\hline$\ldots / 208$ & $-\cdots / 466$ & $---/ 1.78$ & $--/ 0.173$ & $---/ 0.96$ \\
\hline
\end{tabular}


would be proportional to the hold-off time of the switch, so the fourth magnetic switch in the compressor, MS4, was selected to represent a slow switch and the PFL output switch, MS7, was selected to represent a very fast switch. Data reduction algorithms were written to provide a consistent method of calculating the peak charging voltage (the voltage that the input side of the switch would reach were it not to switch out), the hold-off time (the time from onset of charging to switch-out), and the volt-second product (the integral of the charging voltage over the hold-off time). These measurements are summarized in Table 1.

The absolute error bars on the voltage measurement are $\pm 5 \%$, but the shot-to-shot error bars are estimated to be $<1 \%$, so the tabulated values for charge voltage are a very accurate indication of shot-to-shot voltage stability. The timing error bars due to the sample time jitter in the digitizers are negligible and the shot-to-shot error bars due to the data reduction are $<1 \%$ due to the self consistent nature of the algorithm used. Therefore we have a high level of confidence that the measured jitter, of less than $2 \%$ of mean holdoff time in all the data sets, is representative of the value that can be expected for a practical magnetic switch. While this data is preliminary, the single most exciting implication is that it tends to verify the postulation that magnetic switch timing jitter is proportional to the hold-off time. This result was anticipated from an investigation of possible sources of magnetic switch timing jitter, which indicated that variations in the charge voltage would be a dominant source of timing jitter, leading to the proportionality. This means that synchronizing the slow switches in a pair of magnetic modulators is much more critical to the synchronization of the outputs than synchronization of the fast switches. This result is particularly important because the modulator simulations that we did to investigate synchronization schemes revealed that due to timing requirements in active schemes and connection inductance's in switch coupling schemes, synchronization is much more easily accomplished in the slower switching stages. This data was collected at pulse repetition frequencies less than $20 \mathrm{~Hz}$. At higher frequencies, the effects of reflected energy on the charge voltage and the $\mathrm{B}-\mathrm{H}$ state of the switches do not have sufficient time to settle out between pulses, and the chaotic jitter due to these reflections increases, making jitter control even more critical for high repetition rate accelerators.

\section{Sources of Timing Jitter in Magnetic Switches}

The parameters that affect magnetic switch synchronization can be classified as (1) static, referring to factors that either do not change from shot-toshot or that change very slowly; and (2) dynamic, referring to factors that are different from shot-to-shot and that are generally chaotic in nature. Dynamic 
jitter is the main problem when shot-to-shot synchronization of the output pulses of a single magnetic modulator is important. Conversely, both of these types of jitter can cause differences in the timing of the output pulses from a pair of magnetic modulators.

The main sources of static timing variations between two modulators are (1) magnetic switch manufacturing variations such as winding tension that introduces winding stresses that affect the magnetic properties, and packing factor that affects switch hold-off time via the magnetic cross sectional area; (2) temperature dependent magnetic properties that change slowly as the switch initially heats up causing a drift in switch hold-off time; and (3) switch bias point on the $\mathrm{B}-\mathrm{H}$ curve that affects switch hold-off time by changing the available magnetic flux swing. Static jitter parameters are easily corrected by monitoring the time difference in the output pulses from the two compressors and zeroing it either by a one-time setting or continuous gradual adjustment of one of the easily controlled parameters such as magnetic switch bias, trigger timing or charge voltage.

Dynamic jitter is much more difficult to compensate than static jitter because it must be corrected during the course of a shot, and the observables that indicate the necessary correction vary randomly from shot-to-shot. The primary source of dynamic jitter is variation in the initial charge voltage. Charge voltage variations influence magnetic switch timing (hold-off time) through the volt-second product and affects the charge transfer time by altering the discharge inductance to the next stage through the change in operating point on the B-H curve at saturation. The charge voltage of a given magnetic switch stage can vary from shot-to-shot due to oscillations in the prime power supply voltage; timing jitter in the prime switch, which is usually a nonmagnetic technology such as a thyratron or an SCR; timing jitter in preceding magnetic switches, and reflections from the load and down stream compression stages. Timing variations due to fluctuations in the prime switch trigger response can be reduced to well below $1 \sigma=1 \mathrm{~ns}$ by proper choice of the switch and its operating parameters -- thyratrons and SCRs can achieve this. Ripple on the bias supplies can also cause a form of dynamic timing jitter. This type of jitter can be held to acceptable levels by using reasonable bias current filtering, usually in the form of a bias isolation inductor, and by providing sufficient bias to drive the cores well into saturation where the available $\Delta \mathrm{B}$ is less sensitive to current variations. Caution must be used when applying a large bias current because the amount of energy per shot that is extracted from the modulator circuit by the bias network is a function of bias current.

Significant work has been done by others ${ }^{1.6}$ to address dynamic jitter in magnetic modulators. This work has demonstrated that variations in the initial charging voltage due to reflections, ripple on the switch biases and power supply 
fluctuations can be controlled by both precision regulation of the initial charge voltage and electronic trigger delay to the prime switch as a function of the charge voltage and bias current just before a shot. Precision voltage regulation can be achieved using electronic feedback circuitry that causes the first primary switch to commute when the charge voltage on the capacitor that it is charging has reached a specific value ${ }^{2-4}$. The approach hinges on a circuit topology that captures all of the transient energy on the capacitor after the prime switch, away from the magnetic switches, where it can be monitored and controlled just before a shot. It is necessary to localize the residual energy because any energy that is still in the magnetic modulator network will affect switch timing and is difficult to monitor and compensate for. Where sub-nanosecond output timing stability is required, a combination of voltage regulation and electronic trigger delay is required. Active synchronization, such as this, tends to be complicated and if it incorporates a computer it can potentially be slow. In either case active synchronization can only control the timing variations that can be predicted by observation of the initial charge voltage and bias settings.

\section{Dos Lineas Modulator Pair}

A pair of identical magnetic modulators were built and christened "Dos Lineas" at Sandia to test simple, passive jitter control techniques. The circuit topology is shown in Figure 1 and the assembled hardware is shown in Figure 2. Each modulator was designed to run continuously at $100 \mathrm{~Hz}$, with $25 \mathrm{~kW}$ input power and 50\% efficiency to the load. A two stage SCR prime switch powers a 10:140 pulse step-up transformer that drives a two stage magnetic compressor.

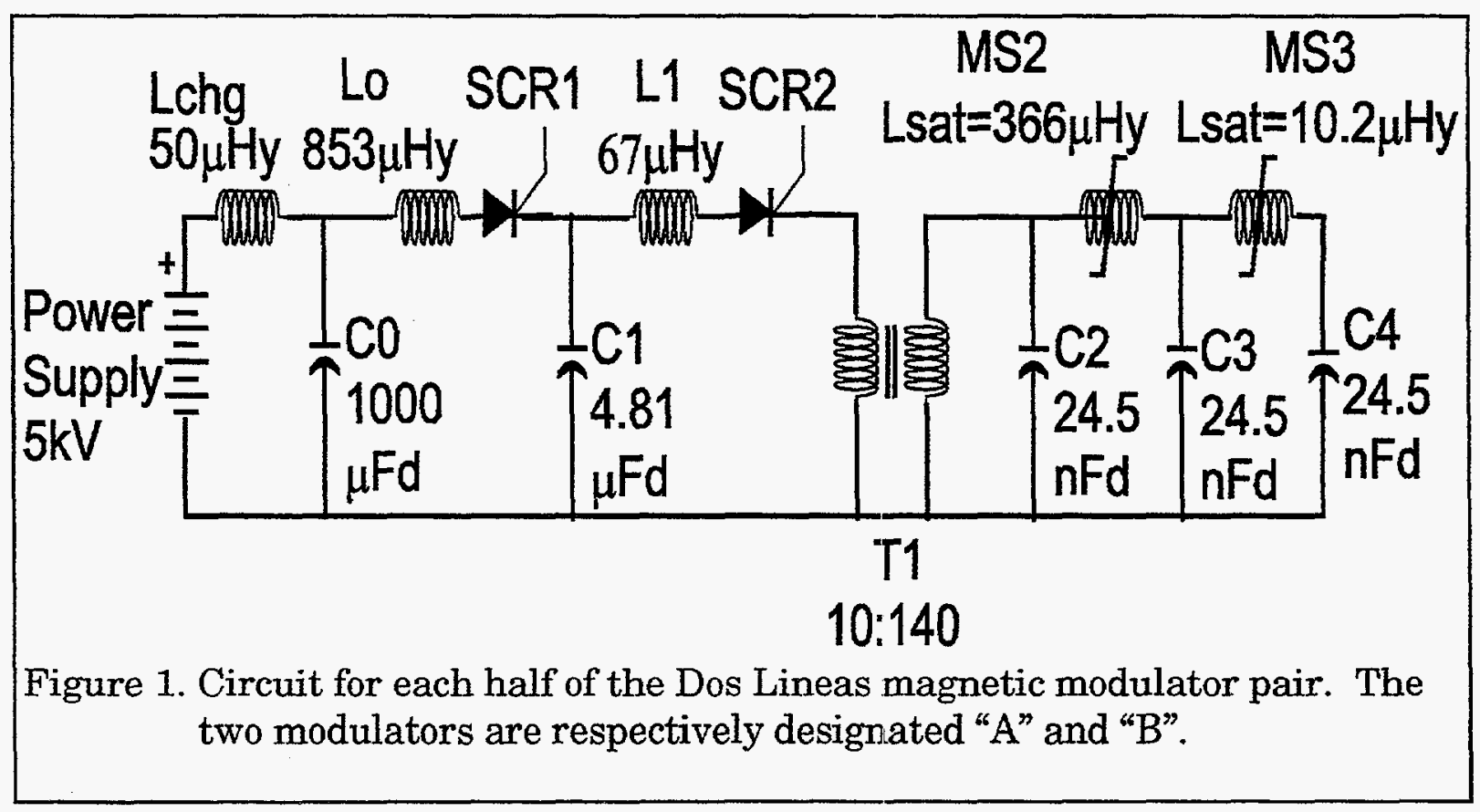




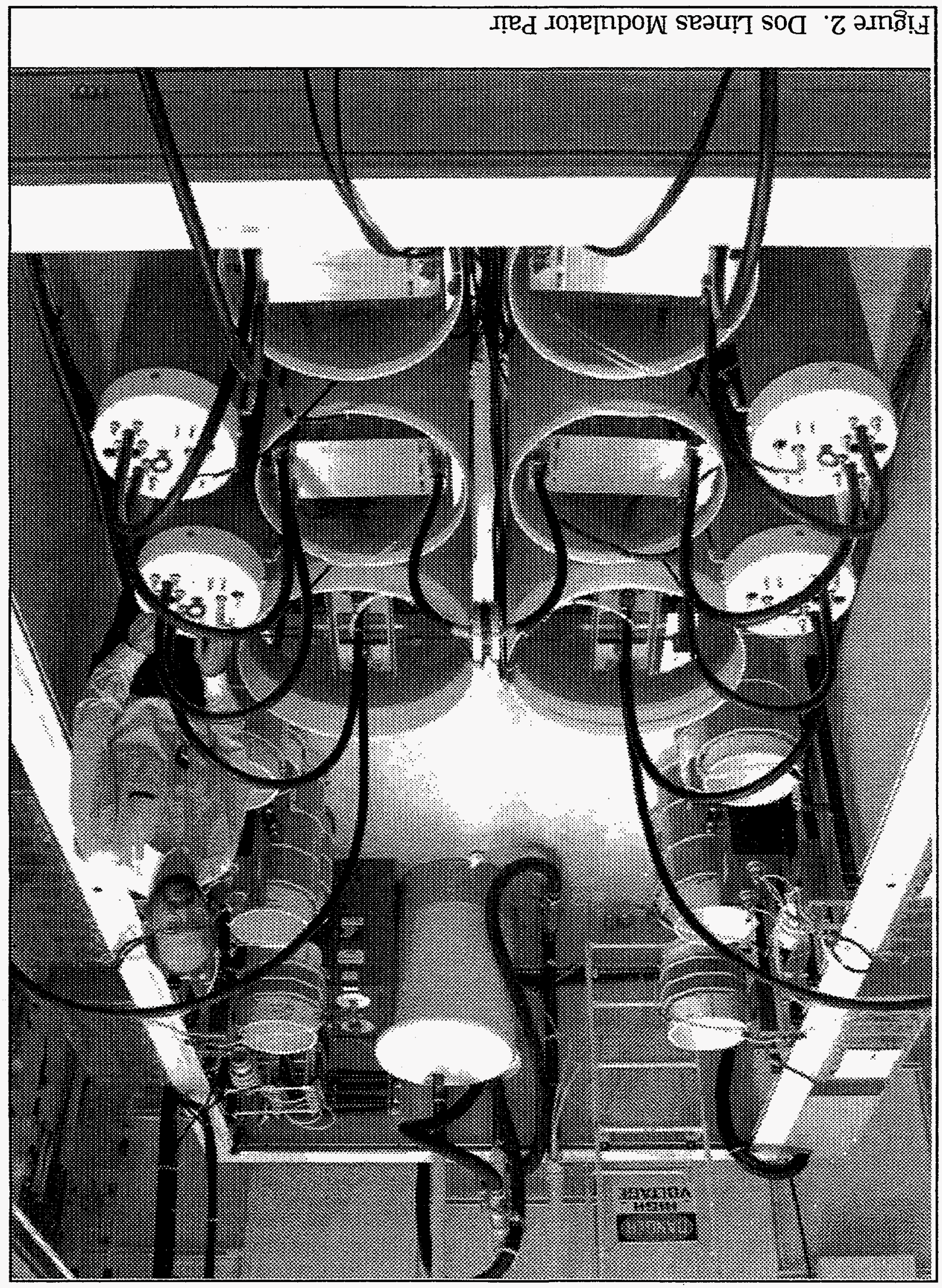


The output voltage pulse is a $1 / 2 \mathrm{~V}_{0}[1-\cos (\pi \mathrm{t} / \tau)]$ charging waveform on a $24.5 \mathrm{nFd}$ capacitor, with a charge time of $1 \mu \mathrm{s}$. To minimize the number of magnetic stages required, the second SCR was designed to discharge as quickly as possible $(40 \mu \mathrm{s})$, subject to the di/dt limits of the device. The switches are equipped with cooling manifolds and channels, Figure 3., but data acquisition was initiated before the plumbing was completed. Without coolant flow, synchronization experiments were conducted using $1 \mathrm{sec}, 100 \mathrm{~Hz}$ bursts. All the data include the effects of a $20 \%$ voltage droop on the first capacitor during the start-up transient.

\section{Reasonable Design Techniques}

The two-stage prime switch topology used for the Dos Lineas modulator pair has been employed by others to drive magnetic modulators using thyratrons ${ }^{2,3,4,7}$. This circuit helps reduce timing variations in the magnetic modulator section. The pair of switches, SCR1 \& SCR2 in Figure 1., form a" charge lock" that allows the first switch to recover before the second switch is triggered. Shunt, resistor-like, LIVA and LINAC core losses and the shunt resistive losses in the water insulated PFL produce reflections in a typical magnetic modulator that preserve the forward direction of the current in the original pulse. At the time of the reflection, the magnetic switches have just switched in the forward direction, so reflections return very quickly to the beginning of the modulator with no switch delays. The second primary switch doesn't have adequate time to commute before the reflected energy arrives at the intermediate storage capacitor, $\mathrm{C} 1$, so the reflected charge is trapped on the negative side of $\mathrm{C} 1$. This charge is transferred to the positive side of $\mathrm{C} 1$ when the first switch closes during the next shot. On the positive side of $\mathrm{C}_{1}$, the charge is at a higher potential than before the reversal occurred, so the reflected energy is recovered along with additional energy that is extracted from the reservoir capacitor, $\mathrm{C} 0$. Trapping the reflections between the non-magnetic primary switches prevents them from stagnating on any of the magnetic switches and causing timing variations. With the advent of large switch mode power supplies, that can be operated in the constant current mode, it is possible to replace the first capacitor, $\mathrm{C} 0$, and the first prime switch, SCR1, with the charging power supply. The intermediate storage capacitor, $\mathrm{C} 1$ is then charged linearly between shots directly by the switch mode power supply. This topology has the advantage that there is no large energy storage on $\mathrm{C} 0$ to contend with. In the arrangement of Figure 1., if both prime switches, SCR1 and SCR2, should accidentally be closed at the same time, a large amount of energy is discharged through these switches and the transformer from the main energy storage capacitor, $\mathrm{C} 1$. This can result in damage to the prime switches. 


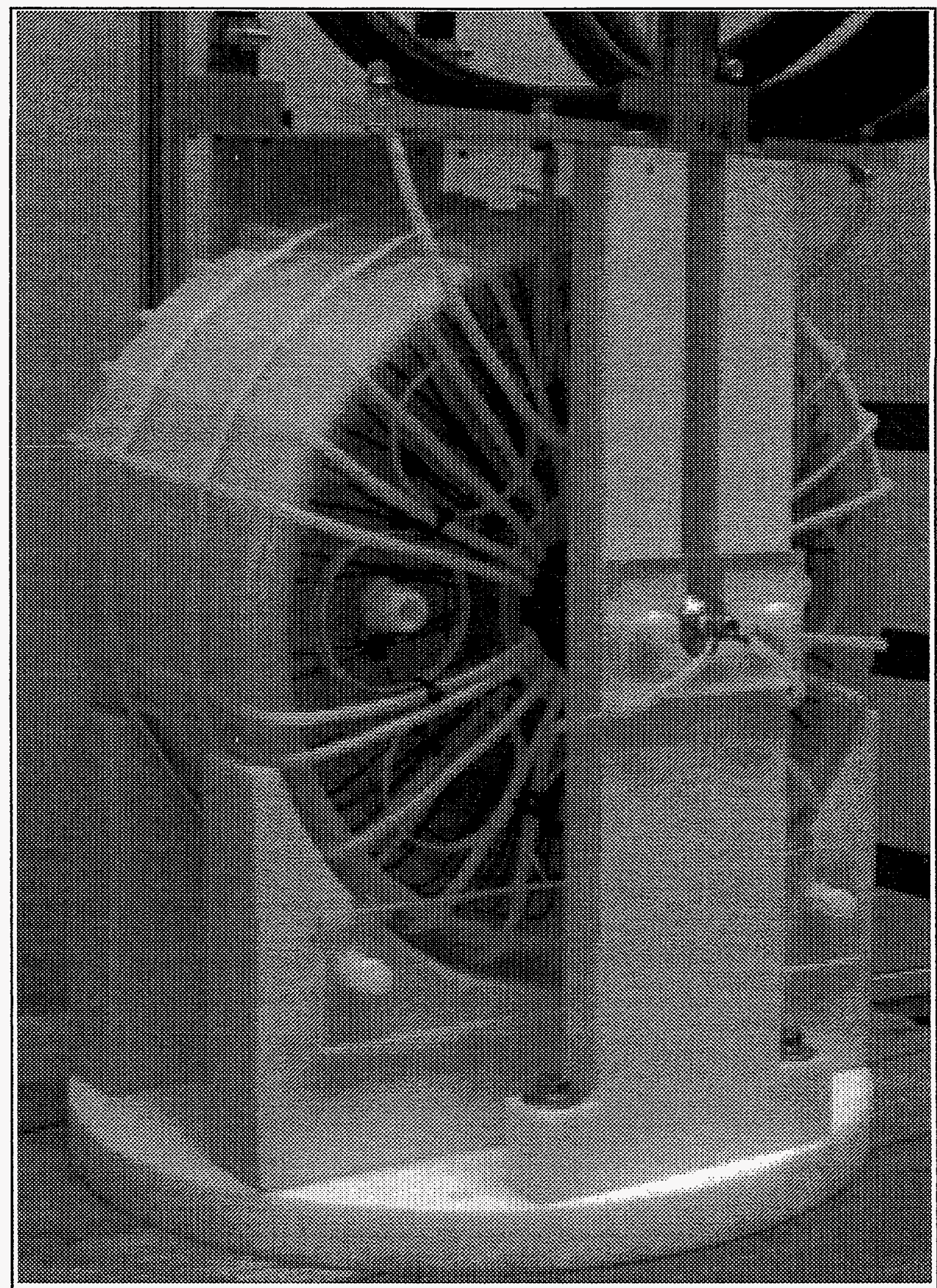

Figure 3. Typical Dos Lineas magnetic switch (MS2). Large outside windings are the coupling windings, main windings are barely visible inside the cooling manifold. 


\section{Results of Dos Lineas Experiments}

The trigger-to-output timing variations on the Dos Lineas modulators were measured by comparing the load voltage to a fiducial ramp that was generated by delaying and integrating the square trigger pulse. The comparison used an algorithm that time shifted one of the waveforms so as to minimize the mean squared difference between the output waveform and fiducial ramp. Steady state was reached for shots 70-99, where the $1 \sigma$ jitter was calculated, Table 2 . Relative timing variations between the outputs of the two machines were measured by comparing the " $\mathrm{A}$ " and " $\mathrm{B}$ " output pulses using the same algorithm. Although it is impossible to say with $\pm 0.5 \mathrm{~ns}$ error bars, the slightly smaller $1 \sigma$ timing jitter between the outputs of machine " $\mathrm{A}$ " and " $\mathrm{B}$ " (Load: $200 \Omega$ ) compared to that between the fiducial and machine "A", may indicate that voltage ripple effects on the common reservoir capacitor, $\mathrm{C} 0$, tend to cancel when the outputs are compared to one another. A better matched load (200 $\Omega$, $24.5 \mathrm{nFd}$ ) reduced the reflections and yielded even lower output jitter. In any case, the $1 \sigma$ steady state time jitter seems to be remarkably small for a pair of modulators that have no jitter compensation circuits and are running from an unregulated power supply. This performance is attributed to ample, well filtered magnetic switch biases and the reflection trapping primary switch topology. The only likely source of time variation in the outputs of the machines is voltage variations on $\mathrm{C} 1$. These voltage variations are due to a combination of power supply ripple, start-up transients and the captured load reflection. The voltage was measured on $\mathrm{C} 1$ just before the second $\mathrm{SCR}$ switched and then converted to the output timing change that it would cause using,

$$
\Delta t_{\text {out }}=\Delta \mathrm{V}_{\mathrm{C} 1} \sum_{\mathbf{n}} \frac{-\left[\mathrm{t}_{\mathrm{SW}}-(\tau / \pi) \sin \left(\pi \mathrm{t}_{\mathrm{SW}} / \tau\right)\right]_{\mathrm{n}}}{\mathrm{V}_{\mathrm{C} 1}\left[1-\cos \left(\pi \mathrm{t}_{\mathrm{sw}} / \tau\right)\right]_{\mathrm{n}}},
$$

n $\quad$ compression stage index

$\tau \quad=$ time to peak

$t_{\mathrm{SW}}=$ time to switch

$\Delta t_{\text {out }}=$ output time shift

$\mathrm{V}_{\mathrm{C} 1}=$ voltage on $\mathrm{C} 1$

$\Delta \mathrm{V}_{\mathrm{C} 1}=$ change in $\mathrm{V}_{\mathrm{C} 1}$ causing output time shift.

Table 2. Steady-State timing jitter for shots 70 through 99 for various cases.

\begin{tabular}{|l|l|l|}
\hline Case $\quad($ Load $)$ & Range of $1 \sigma$ Std. [ns] $\pm 0.5 \mathrm{~ns}$ \\
\hline Machine A vs Fidu $\quad(200 \Omega)$ & 2.1 to 2.5 \\
\hline Machine A vs B $\quad(200 \Omega)$ & 1.9 to 2.3 \\
\hline Machine A vs B $\quad(200 \Omega, 24.5 \mathrm{nFd})$ & 0.7 to 1.0 \\
\hline $\begin{array}{l}\text { Machine A vs B } \quad(200 \Omega, 24.5 \mathrm{nFd}) \\
\text { with Magnetic Coupling }\end{array}$ & $\cong 0.1$ All Tests with Magnetic Coupling \\
\hline
\end{tabular}




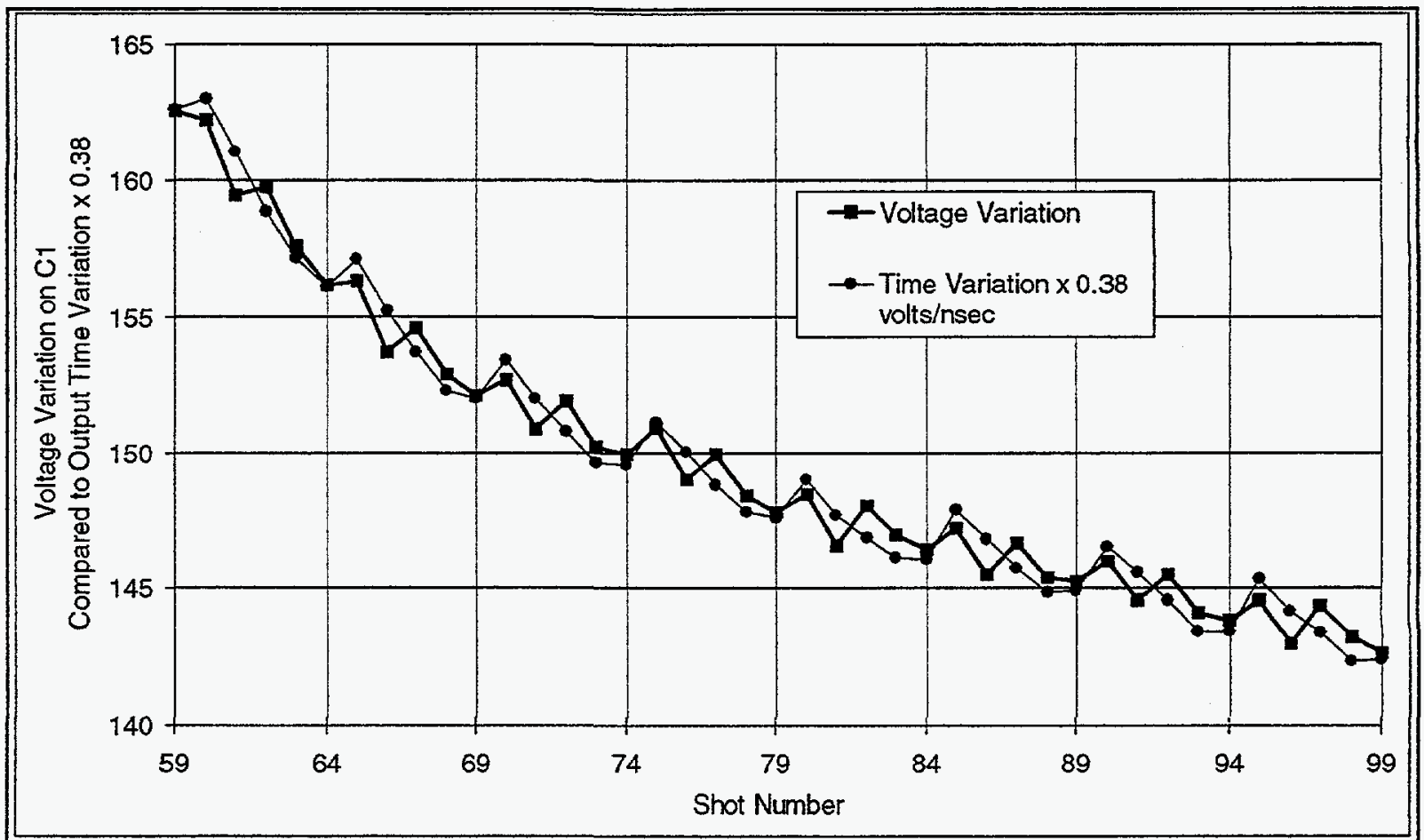

Figure 4. Comparison of voltage ripple on $\mathrm{C} 1$ with $0.38 \times t_{\text {out }}$ indicates that the output timing jitter is mainly due to ripple on the initial charge voltage.

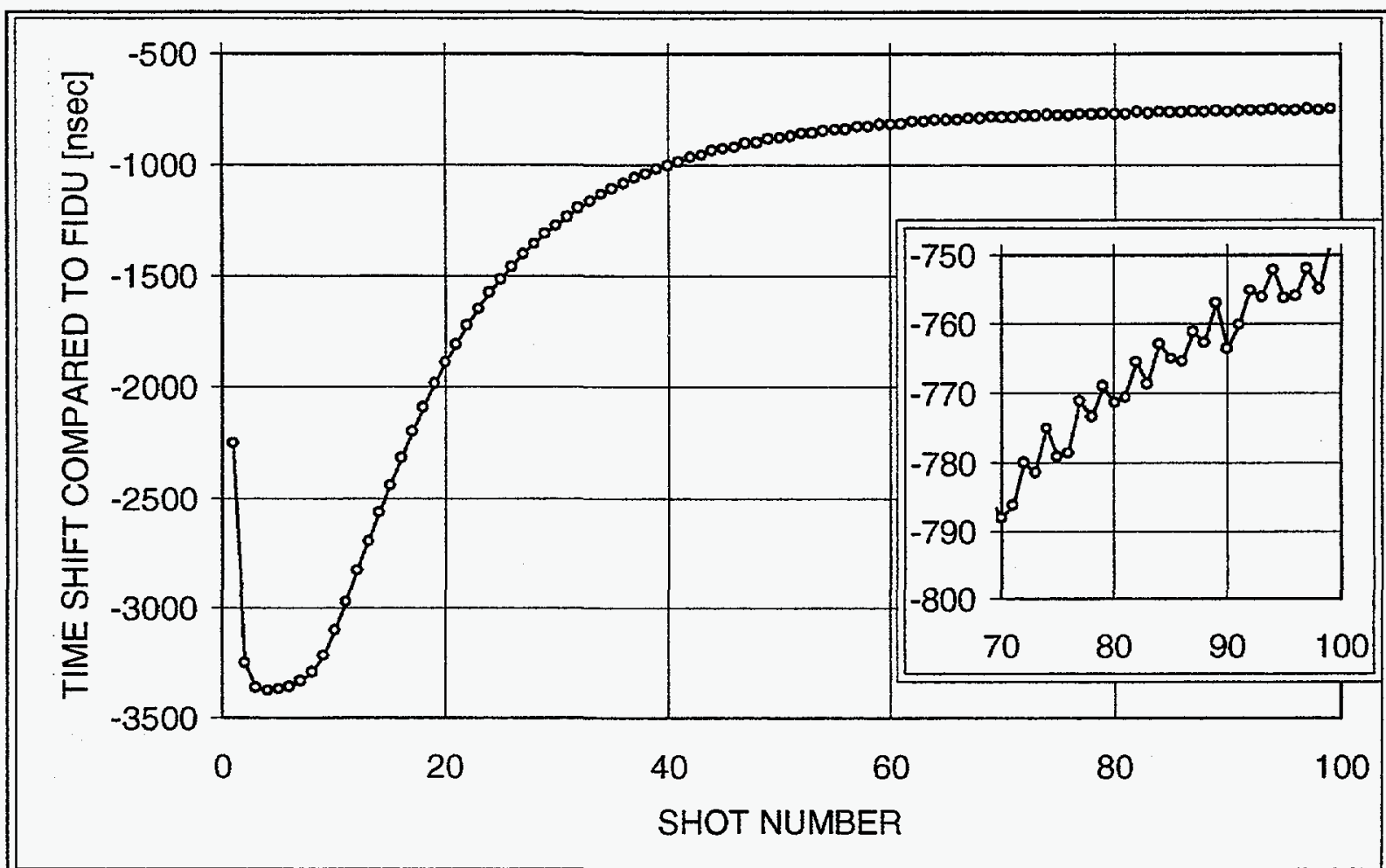

Figure 5. Measured output time-shift on modulator " $\mathrm{A}$ " relative to trigger pulse. Inset is detail of shots 70 through 100 . 
yielding a scale factor of $\Delta \mathrm{V}_{\mathrm{Cl}} / \Delta \mathrm{t}_{\text {out }}=0.38 \mathrm{volts} / \mathrm{ns}$. A comparison of the measured voltage ripple on $\mathrm{C} 1$ to the scaled output timing jitter on the " $\mathrm{A}$ " modulator is shown in Figure 4. The time jitter calculated from the voltage ripple on $\mathrm{C} 1$ from two different burst runs was $1 \sigma=1.6 \mathrm{~ns} \& 2.0 \mathrm{~ns}$ compared to the measured time jitter of $1 \sigma=2.1 n s \& 2.1 n s$. Furthermore, the decay time constant in Figure 4. of the voltage on C1 matches the time constant of the scaled output delay, tout $\times 0.38$ volts/ns,.exactly. This indicates that to within our ability to measure, the output time variations are due to voltage variations on C1. If there are other jitter components such as trigger jitter in the SCRs, they are very small. A typical plot of the timing variation between the output of one of the modulators and the fiducial is shown in Figure 5. The initial advancement in the output time corresponds to an increase in the charge voltage on $\mathrm{C} 1$ at the onset of repetitive operation, due to energy recovery. The voltage on $\mathrm{C} 1$ increases most between the first and second shots and then continues to increase more slowly as the higher input charge causes a proportionate increase in the reflection. The voltage and hence the output timing advance falls off as the voltage drop in the wires between $\mathrm{C} 0$ and the charging power supply begin to dominate.

\section{Synchronization by Magnetic Coupling}

A simple, passive, maintenance free technique for synchronizing independent magnetic switches and modulators has been developed. Two similar magnetic switches can be made to switch together by applying equal windings to both and then interconnecting them symmetrically, Figure 6 . No current flows in the coupling winding if the switches charge together and switch together. If one switch starts to charge before the other, the transformer action of the coupling winding causes the other switch to begin to charge as well. This tends to

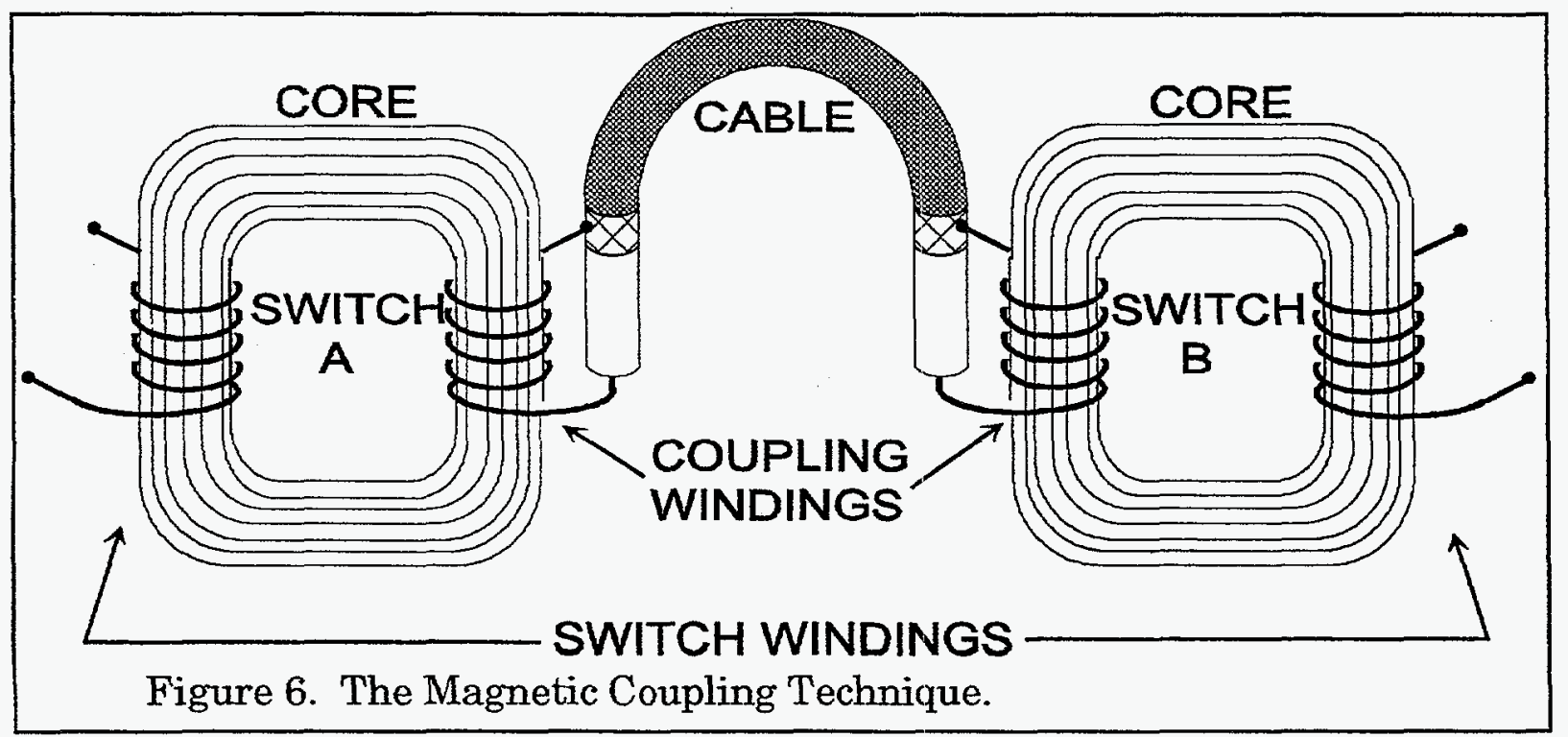


equalize the charge voltage on corresponding stages of both modulators. If then for any reason at all one switches before the other, the coupling winding acts as a shorted secondary on the slow switch and forces it into a low inductance or switched state.

\section{PSPICE Simulations}

PSPICE simulations of a two stage modulator with both magnetic switching stages magnetically coupled using ten turns each, were conducted to investigate the effectiveness of the technique. The circuit topology used was identical to the part of the Dos Lineas modulator circuit that follows the transformer in Figure 10. Results of these simulations are shown in Figures 7 through 9. In these figures, each pair of curves represent the capacitor charge voltages on corresponding stages of the two different modulators. The knee at the top of the curves is where switching occurs, so the switching times of corresponding stages in the different modulators can be compared by observing the time differentials between corresponding knees. Figure 7(a) shows the effect of a $2 \%$ difference in the packing factors of corresponding switches in the two uncoupled modulators, and Figure 7(b), shows how the magnetic coupling brings the switching times of corresponding stages back into alignment. Figure 8(a) shows the effect on switch timing of a 7\% initial charge difference at the inputs of the two uncoupled modulators, and Figure 8(b) shows how the magnetic coupling compensates for the difference. Figure 9(a) shows the effect of triggering the " $\mathrm{A}$ " modulator $1 \mu \mathrm{s}$ after modulator " $B$ " when the modulators are uncoupled, and Figure $9(\mathrm{~b})$ shows how magnetic coupling brings the switching times of corresponding stages of the two modulators back into correspondence. Changes in packing factor, Figure 7, and charge voltage, Figure 8 , both cause a difference in the peak charge voltage of corresponding stages of the uncoupled modulators, however, the simulations show the tendency of the magnetic coupling to compensate for this effect and equalize the peak charge voltages on corresponding stages of a magnetically coupled modulator pair.

\section{Demonstration of Magnetic Coupling}

Ten-turn coupling windings were installed between machines $A$ and $B$ on corresponding switches of both magnetic compression stages, Figure 10. The baseline (no attempt was made to deliberately disrupt synchronization) output timing offset between the Dos Lineas modulators is compared with and without magnetic coupling in Figure 11. The start-up timing transient on the data set without magnetic coupling is mainly due to the voltage transient on $\mathrm{C} 0$. There is a small residual start-up transient with magnetic coupling that is believed to be caused by modulation of the saturated inductance's in the output switches 


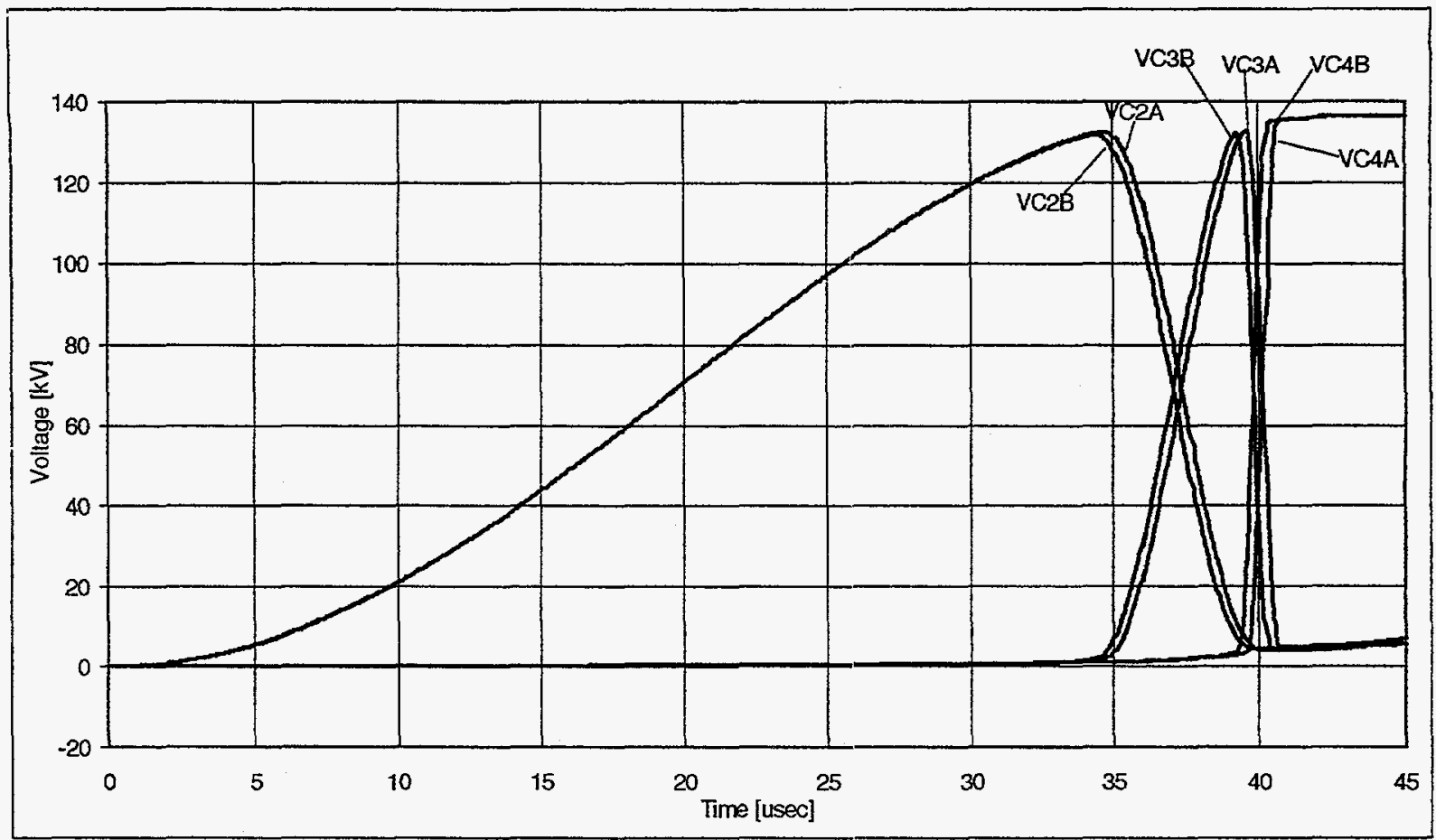

(a)

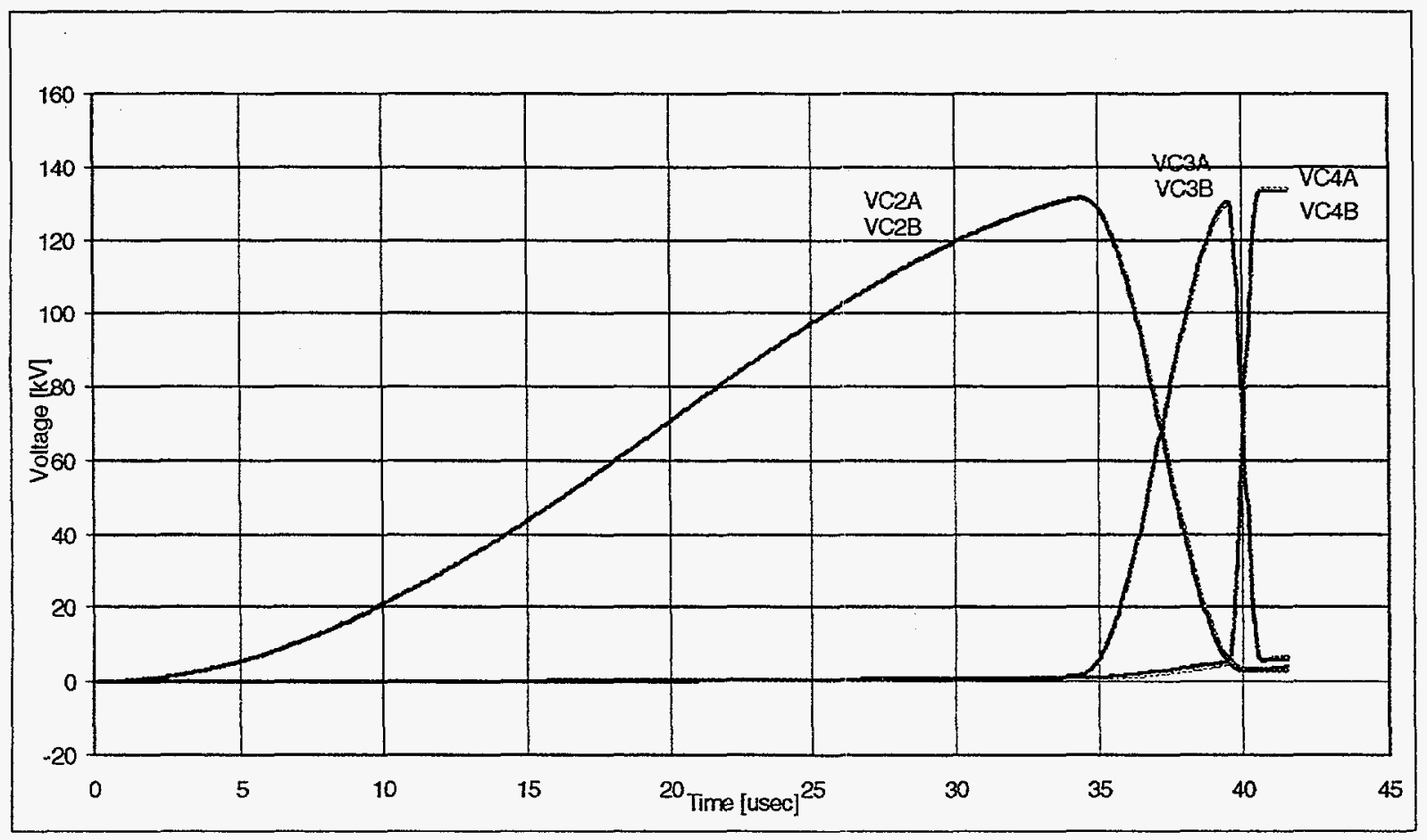

(b)

Figure 7. PSPICE simulation of two stage magnetic modulator pair. Modulator "A" switches have $2 \%$ more packing factor than modulator " $\mathrm{B}$ " switches: (a) without magnetic coupling, (b) with magnetic coupling. 


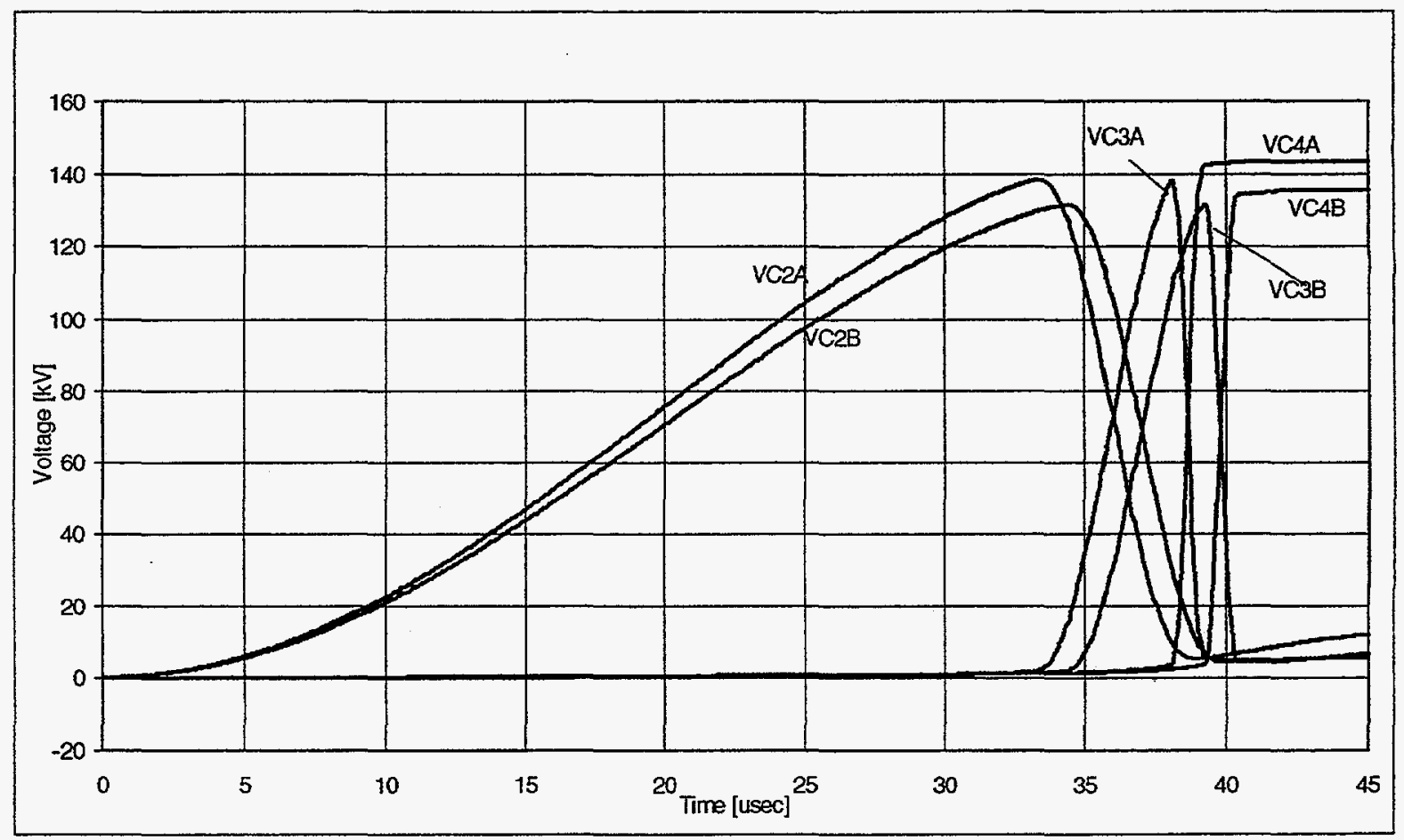

(a)

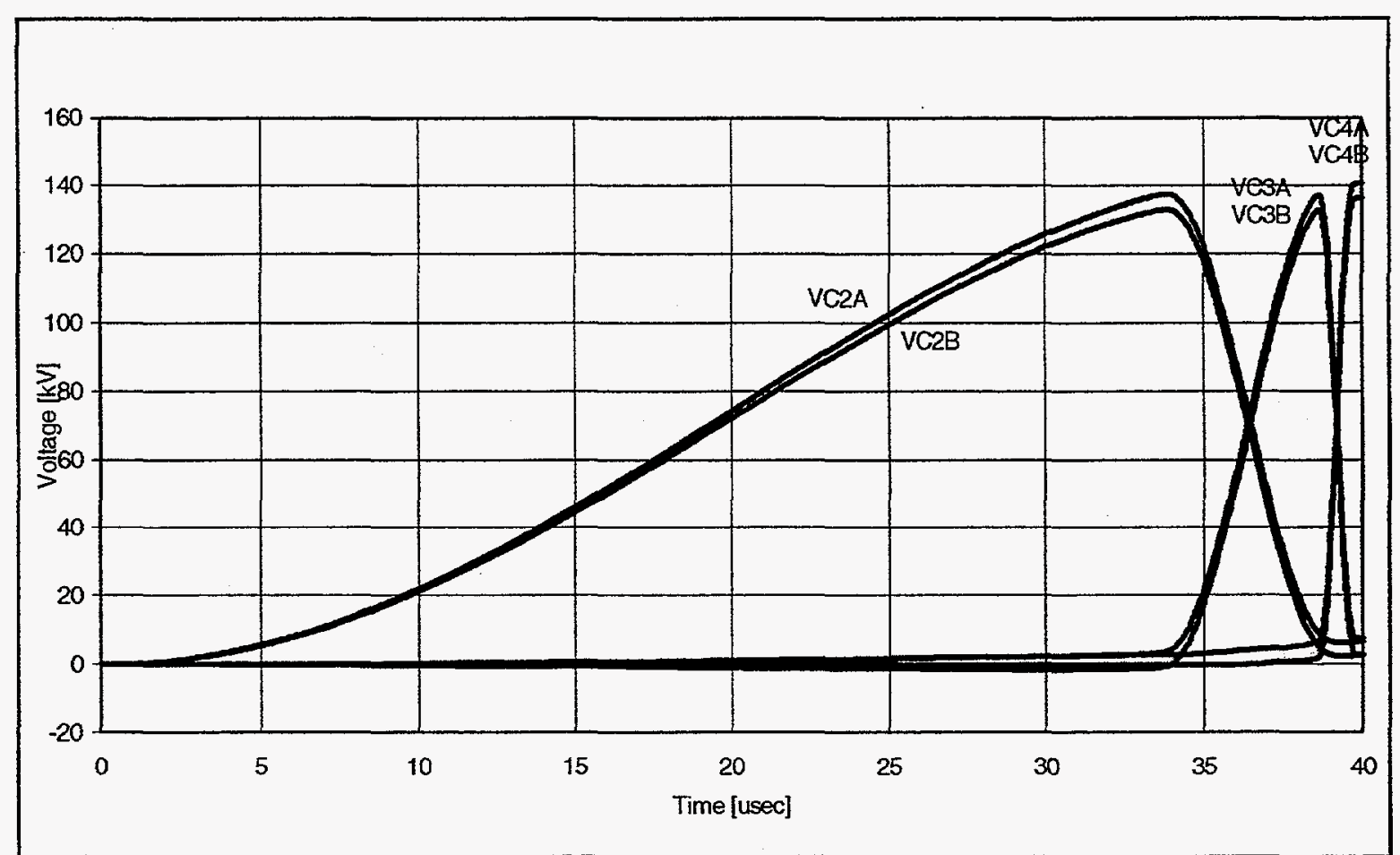

(b)

Figure 8. PSPICE simulation of two stage magnetic modulator pair. Modulator " $A$ " is charged $7 \%$ higher than modulator " $B$ ": (a) without magnetic coupling, (b) with magnetic coupling. 


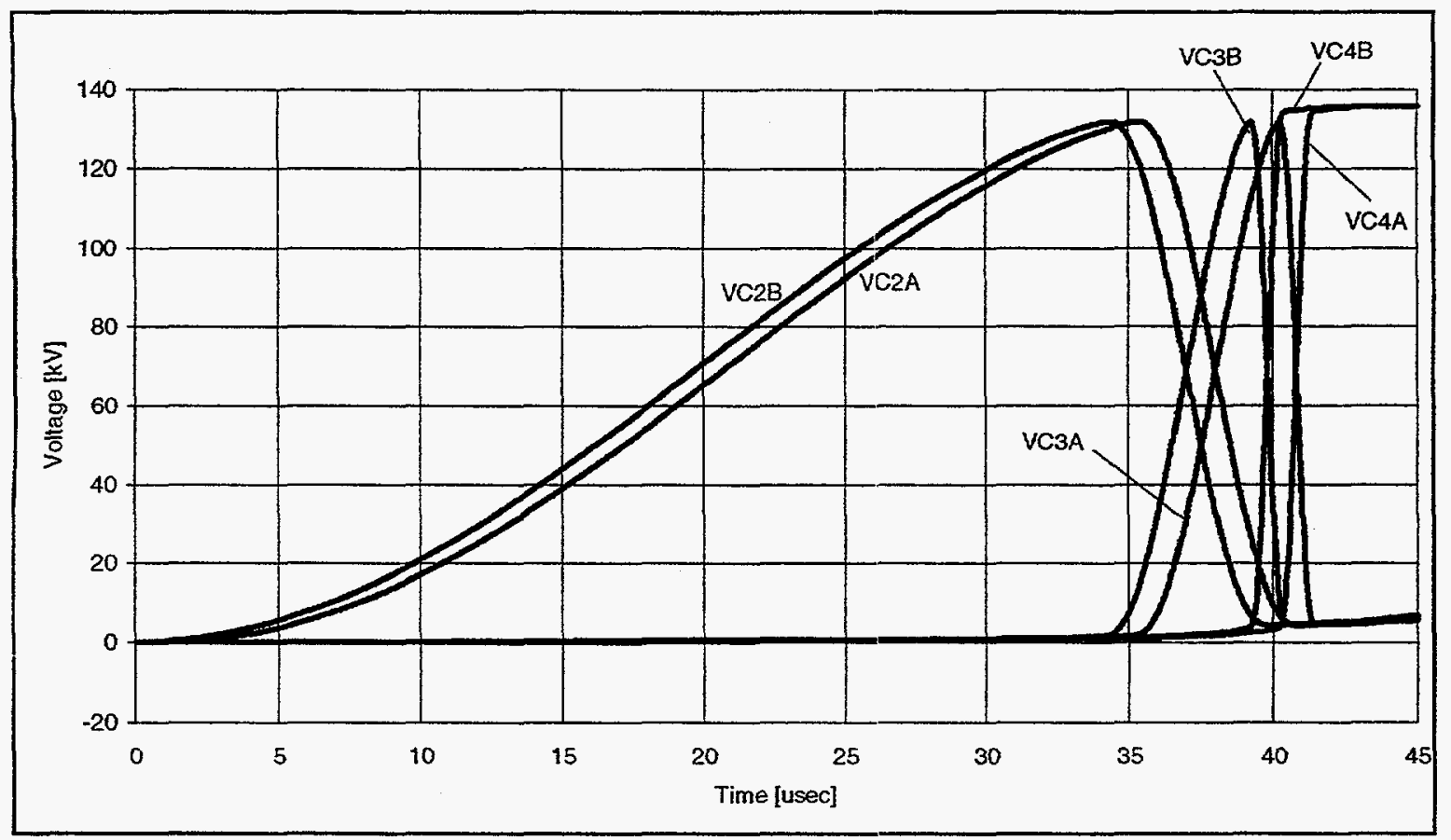

(a)

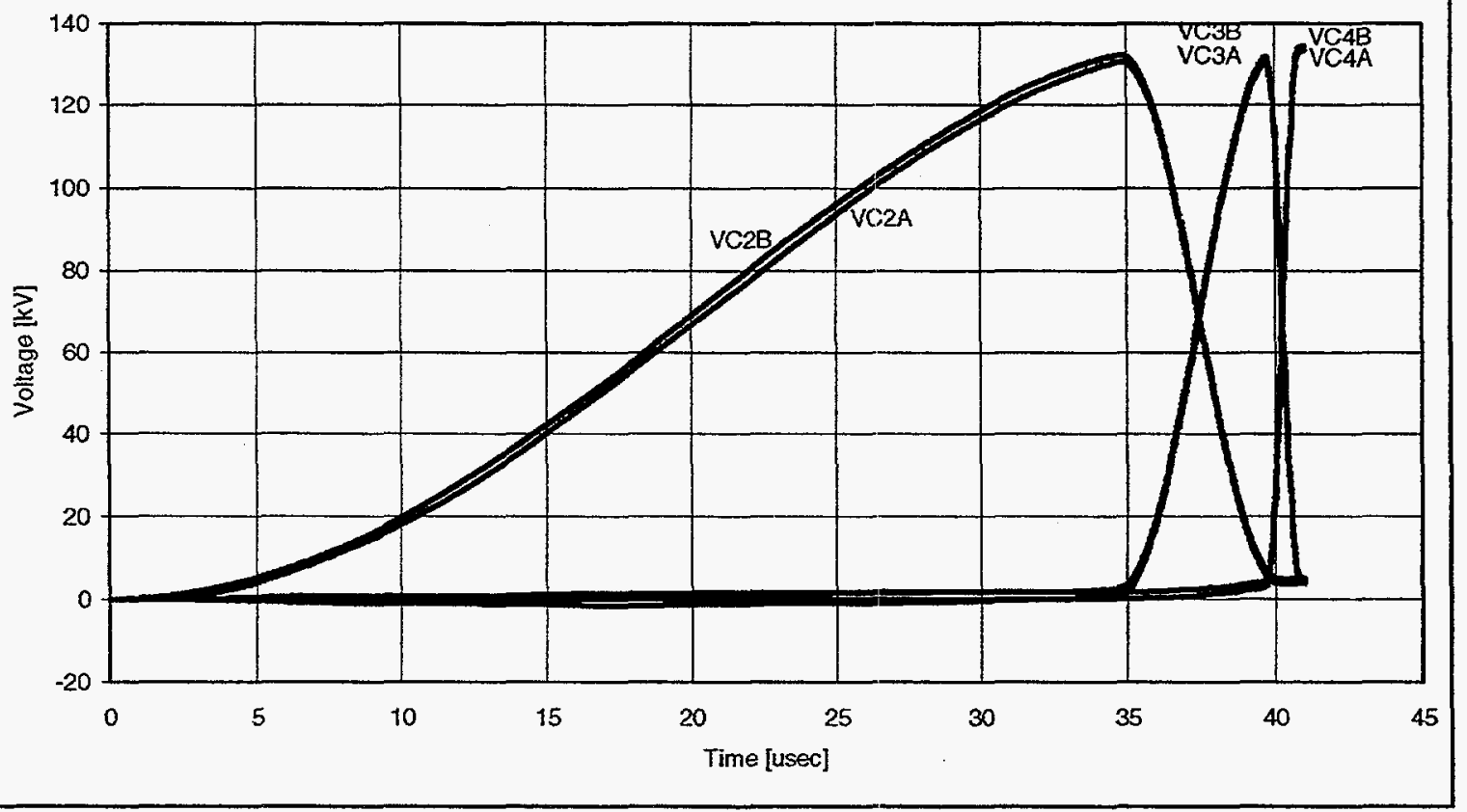

(b)

Figure 9. PSPICE simulation of two stage magnetic modulator pair. Modulator " $A$ " is triggered $1 \mu$ s after modulator " $B$ ": (a) without magnetic coupling, (b) with magnetic coupling. 


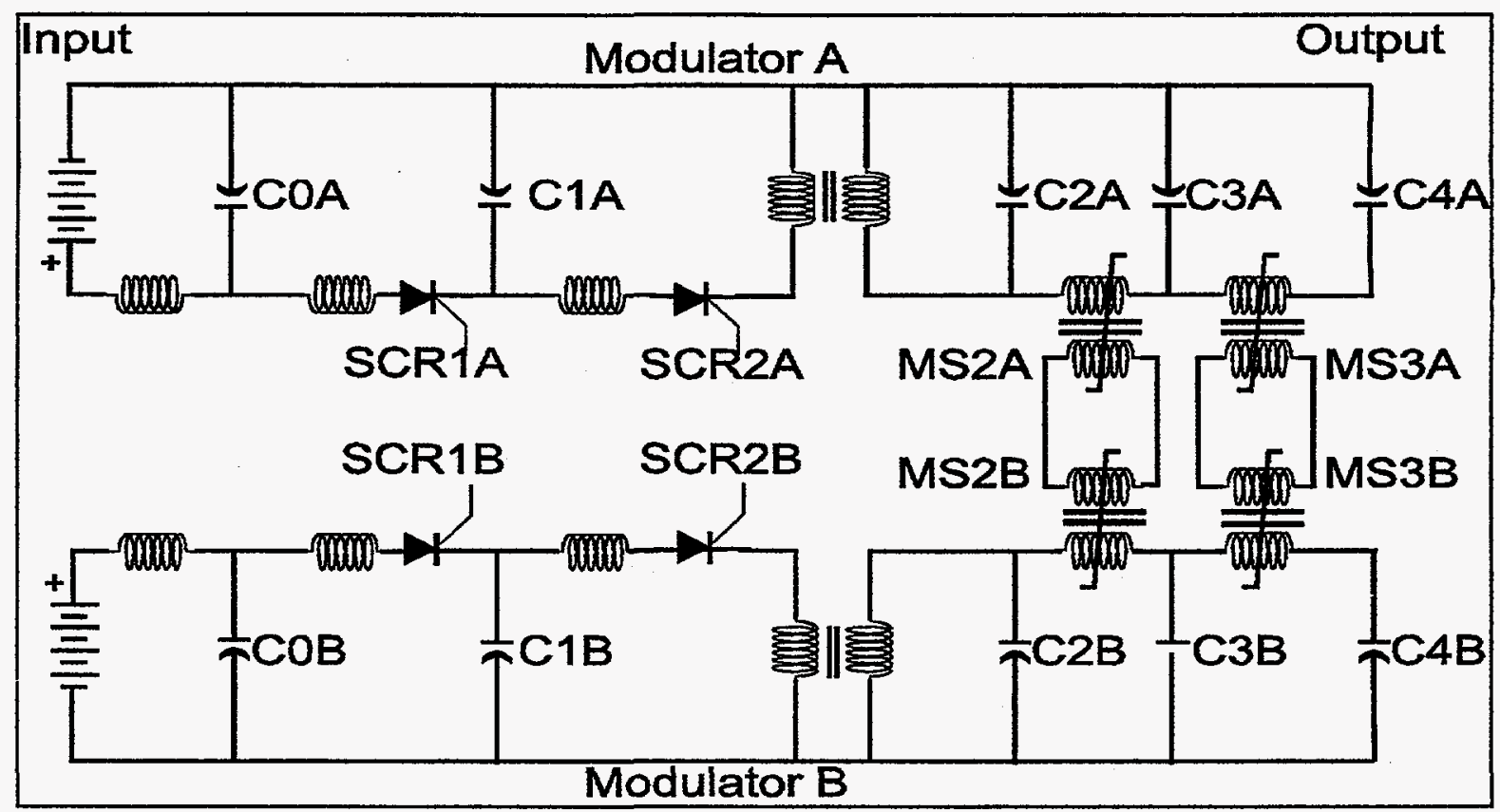

Figure 10. Dos Lineas circuit with magnetic coupling between MS2A \& MS2B and between MS3A \& MS3B

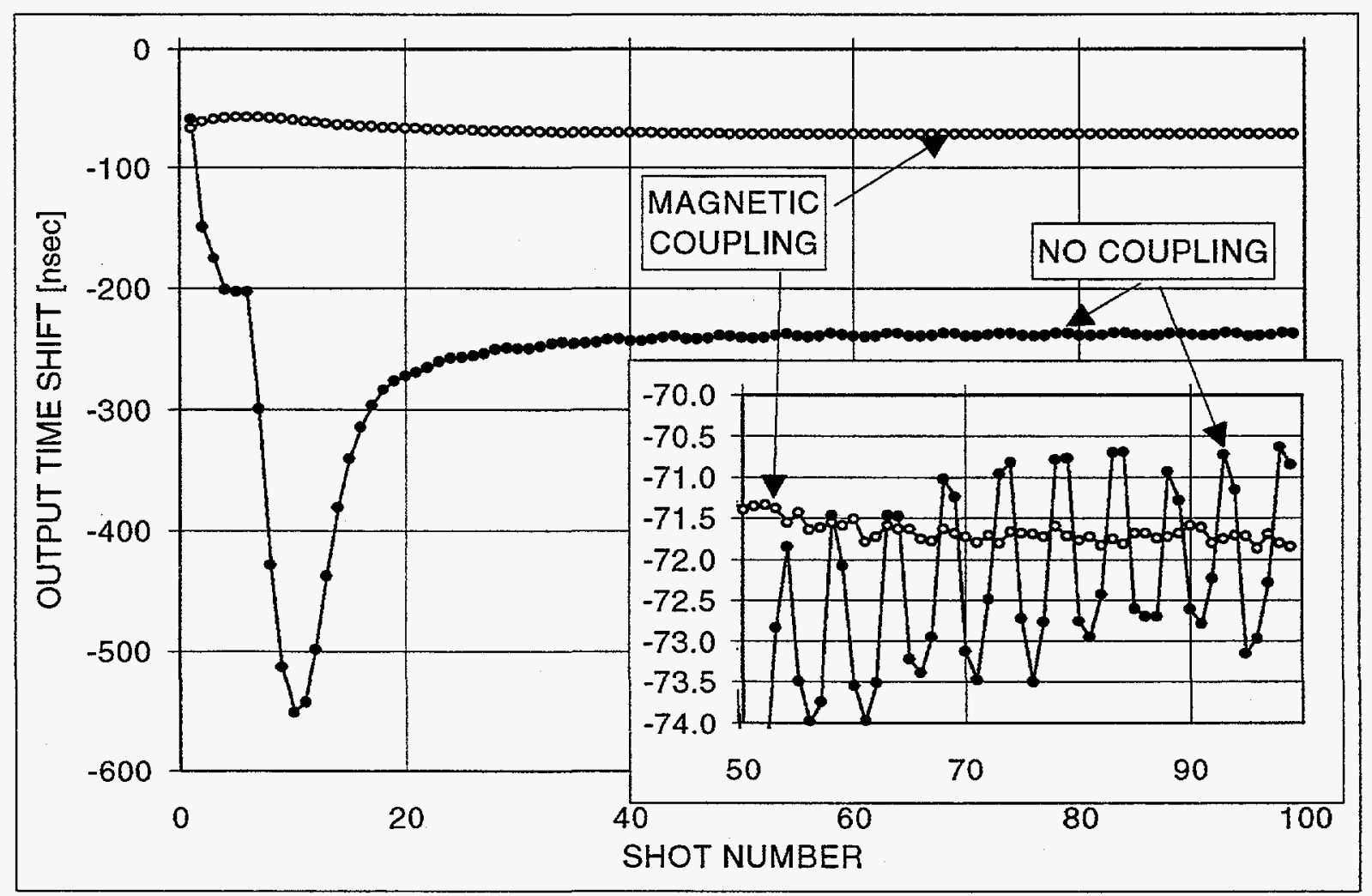

Figure 11. Effect of magnetic coupling on transient and on random jitter between Dos Lineas outputs. Inset shows expanded view of shots 50-100. (Uncoupled data was shifted up in inset) 
due to the variation in the operating point. The varying inductance's change the widths of the output current pulses that the algorithm compares to obtain the relative time shift between the two machine outputs, resulting in the timing offset. Since minimizing the RMS difference between the machine output current pulses yields the time shift that centers the current pulses on each other, a relative width change on pulses that are forced to start at the same time by the magnetic coupling, causes an apparent time shift to result from our algorithm. The inset in Figure 11 shows the ripple in the time shift between the outputs of the two machines. Without coupling this time shift has a $1 \sigma$ jitter of $1.0 \mathrm{~ns}$, but with magnetic coupling the jitter is reduced to $1 \sigma=0.07 \mathrm{~ns}$. We found that in all of our tests with magnetic coupling, the timing on the " $\mathrm{A}$ " output is locked to 60 $\mathrm{ns}$ before the " $\mathrm{B}$ " output. This fixed time shift is due to the round-trip propagation delay in the coupling circuit. This was determined by calculations for a helical transmission line with the ground housing far from the helical winding, yielding an approximate round-trip delay of $62 \mathrm{~ns}$ for the coupling winding 8 . The saturated inductance of the first magnetic switch on the "A" side is slightly less than that on the "B" side. Since these switches are coupled, they switch together and the A side always reaches the volt-second product of the " $\mathrm{A}$ " output switch first. Thus, regardless of whether machine " $A$ " is triggered before or after "B", the "A" output always leads the "B" output by the fixed geometrical delay in the coupling winding between the output switches -- give or take the apparent delay caused by modulation of the saturated inductance's in the output switches. On different days, our operating point varied enough to make this time shift between machine " $\mathrm{A}$ " and " $\mathrm{B}$ " vary by a total spread of $3.5 \mathrm{~ns}$ across all of our data.

In addition to comparing transients and jitter with and without coupling, two additional tests were conducted to experimentally evaluate the effectiveness of magnetic coupling. First, trigger offsets were introduced between the two machines of $\pm 1 \mu \mathrm{s}$, and second a $6.5 \%$ difference in charge voltage was introduced at the inputs of the two machines. Typical timing differences between the two machine outputs for both of these cases are presented in Figures 12 and 13 respectively.

The $1 \mu \mathrm{s}$ time shift that was introduced between the triggers of the two machines is clearly visible in the uncoupled data of Figure 12, but has been completely eliminated in the data with coupling. The inset of Figure 12 shows that magnetic coupling reduces steady-state time-shift ripple from $1 \sigma=0.72 \mathrm{~ns}$ to $1 \sigma=0.07 \mathrm{~ns}$, which is consistent within our error-bars with the baseline data of Figure 11.

A steady state voltage offset between the inputs of the two machines yields a steady state timing offset between the outputs of the two machines, as shown in Figure 13. The standard deviation of the steady state timing ripple 


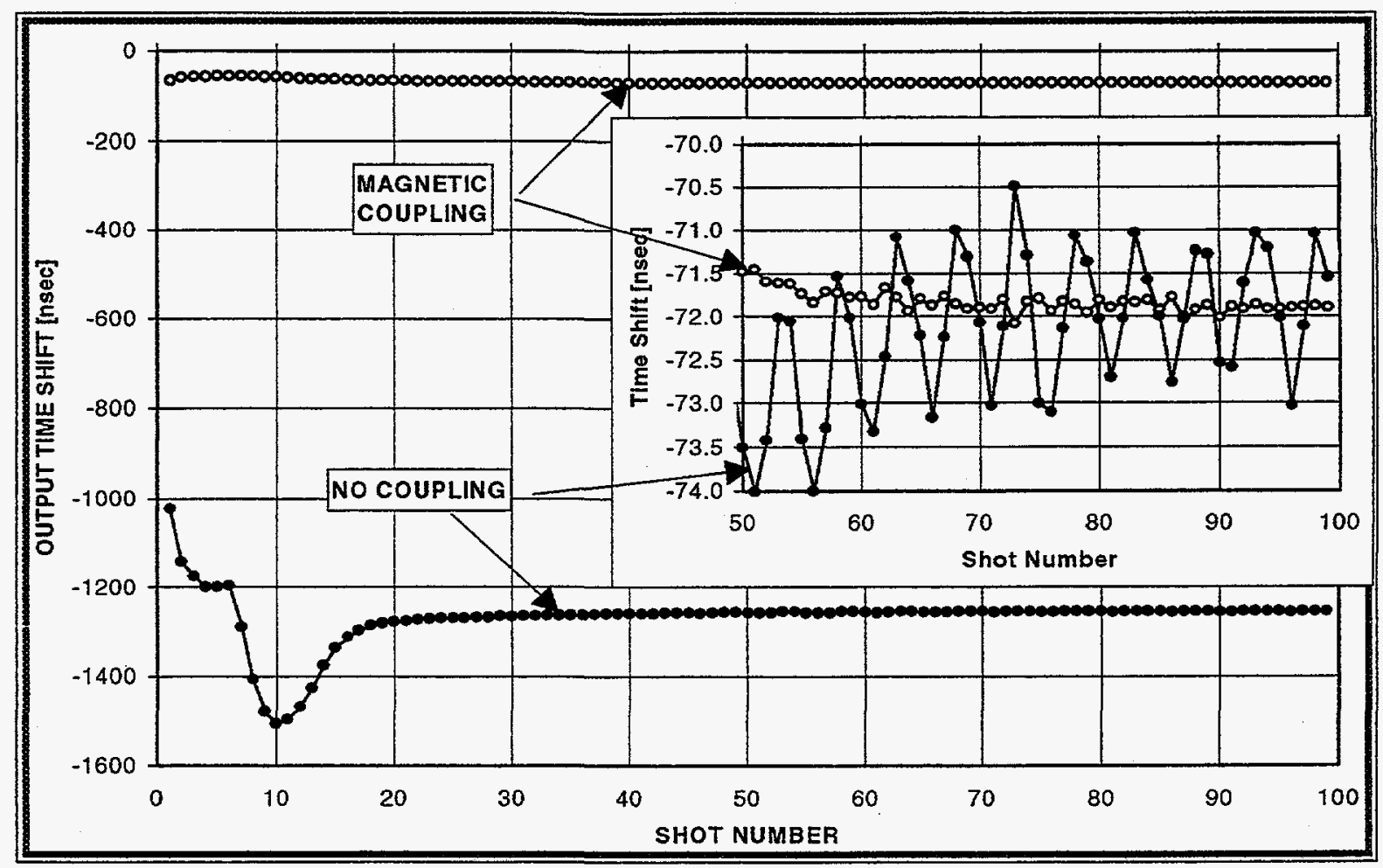

Figure 12. Output time shift between modulator " $A$ " and " $B$ " with modulator " $A$ " triggered $1 \mu$ s before modulator " $\mathrm{B}$ ".

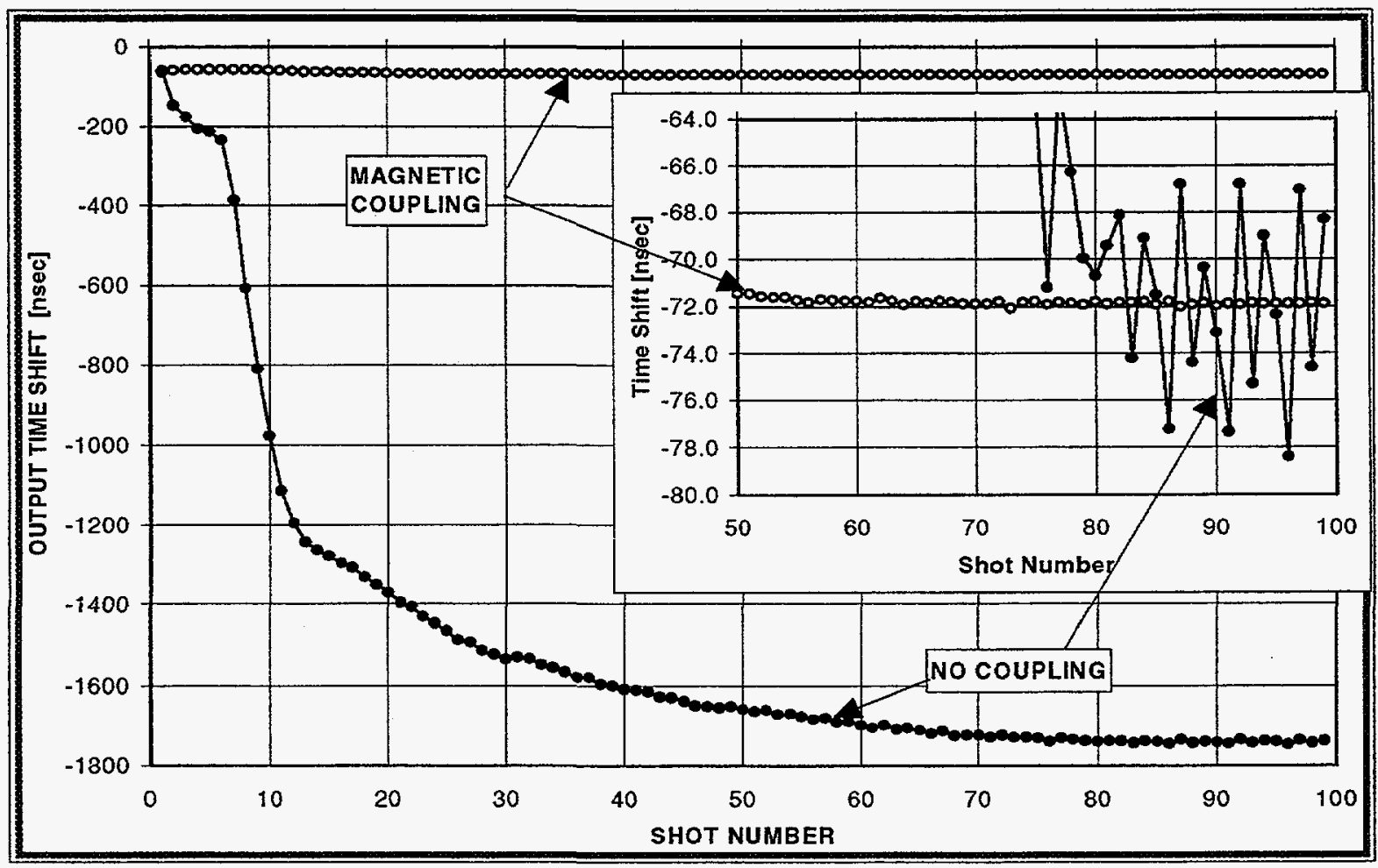

Figure 13. Output time shift between modulator " $\mathrm{A}$ " and " $\mathrm{B}$ " with modulator " $\mathrm{A}$ " charged 324 volts higher then modulator " $\mathrm{B}$ ". 
between the outputs of the two machines with magnetic coupling is still $1 \sigma=$ $0.07 \mathrm{~ns}$ as in the preceding data. Conversely, there is an increased timing ripple of $1 \sigma=6.3 \mathrm{~ns}$ between the outputs of the two machines without coupling. This result is explained by the fact that the $\mathrm{C} 0$ capacitor that was shared in the preceding data, had to be separated into $\mathrm{COA}$ and $\mathrm{C} 0 \mathrm{~B}$ so that separate input charging voltages could be applied to the separate machines. When the $\mathrm{C} 0$ capacitor is shared, the effect on output timing of input voltage ripple tends to cancel. The only reason that the effect of this ripple doesn't completely cancel when both machine inputs are fed by a common node, is that the time delay through each machine is a non-linear function of the operating points of the magnetic switches it is composed of. Fabrication and bias differences between the two machines result in different operating points, even with the same initial charge voltage. Therefore, a change in voltage on the input of one machine produces a different transit time through that machine than the same voltage change produces on the other machine. As indicated in Table 2, in all of these tests the measured time-shifts and time-shift ripple between the outputs of the two machines with coupling were identical to the baseline results with coupling, in Figure 11.

\section{Effect of Magnetic Coupling on Uncoupled Down-Stream Switches}

When there is an imbalance between the two machines, the first stage to be affected by the imbalance transmits a small feed-forward current (15 $\mathrm{A}$ in the first coupling network for a $1 \mu \mathrm{s}$ trigger offset) through the coupling network to the next down stream stage. If the next stage is magnetically coupled this current has no effect and it is shunted through that stages coupling network, and so on. If the next down stream stage is not coupled, then the feed-forward current causes a voltage foot on the input of the uncoupled switches. To test the effect of this voltage foot on the timing of an uncoupled switch pair being driven by a coupled modulator pair, we uncoupled the second magnetic switch pair (its hold-off time is $6.7 \mu \mathrm{s}$ ), leaving the first pair coupled. We then introduced a trigger offset between the machines that ranged from $-500 \mathrm{~ns}$ to $500 \mathrm{~ns}$. In response to the voltage foot generated by a $100 \mathrm{~ns}$ trigger timing offset, the timing variation at the output of the uncoupled switch shifted only $4 \mathrm{~ns}$, Figure 14. This timing offset represents $0.06 \%$ of the hold-off time of the uncoupled switch, to which it is proportional. In an actual application, the first switch that might be difficult to couple would be a closed geometry switch with a hold-off time of about $1 \mu \mathrm{s}$. Thus, the $\pm 100 \mathrm{~ns}$ trigger offset would result in $\pm 0.6 \mathrm{~ns}$ output timing variation. PSPICE simulations indicate that this offset can be greatly reduced by increasing the bias on the uncoupled switch to compensate for the volt-seconds applied by the foot. 


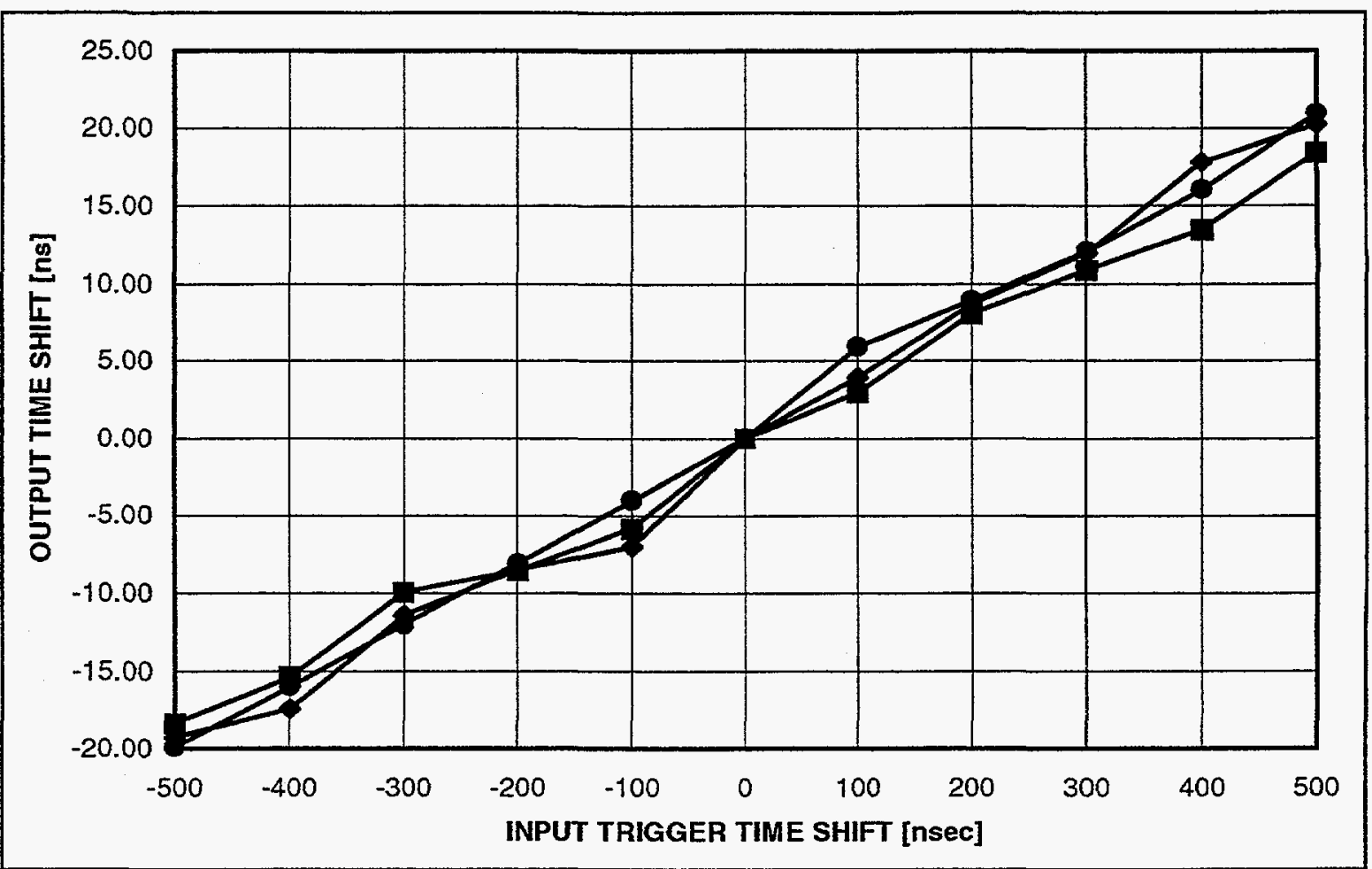

Figure 14. Output time shift between modulator " $\mathrm{A}$ " and " $\mathrm{B}$ " with MS2A \& B coupled and MS3A \& B not coupled as a function of input trigger timing offset.

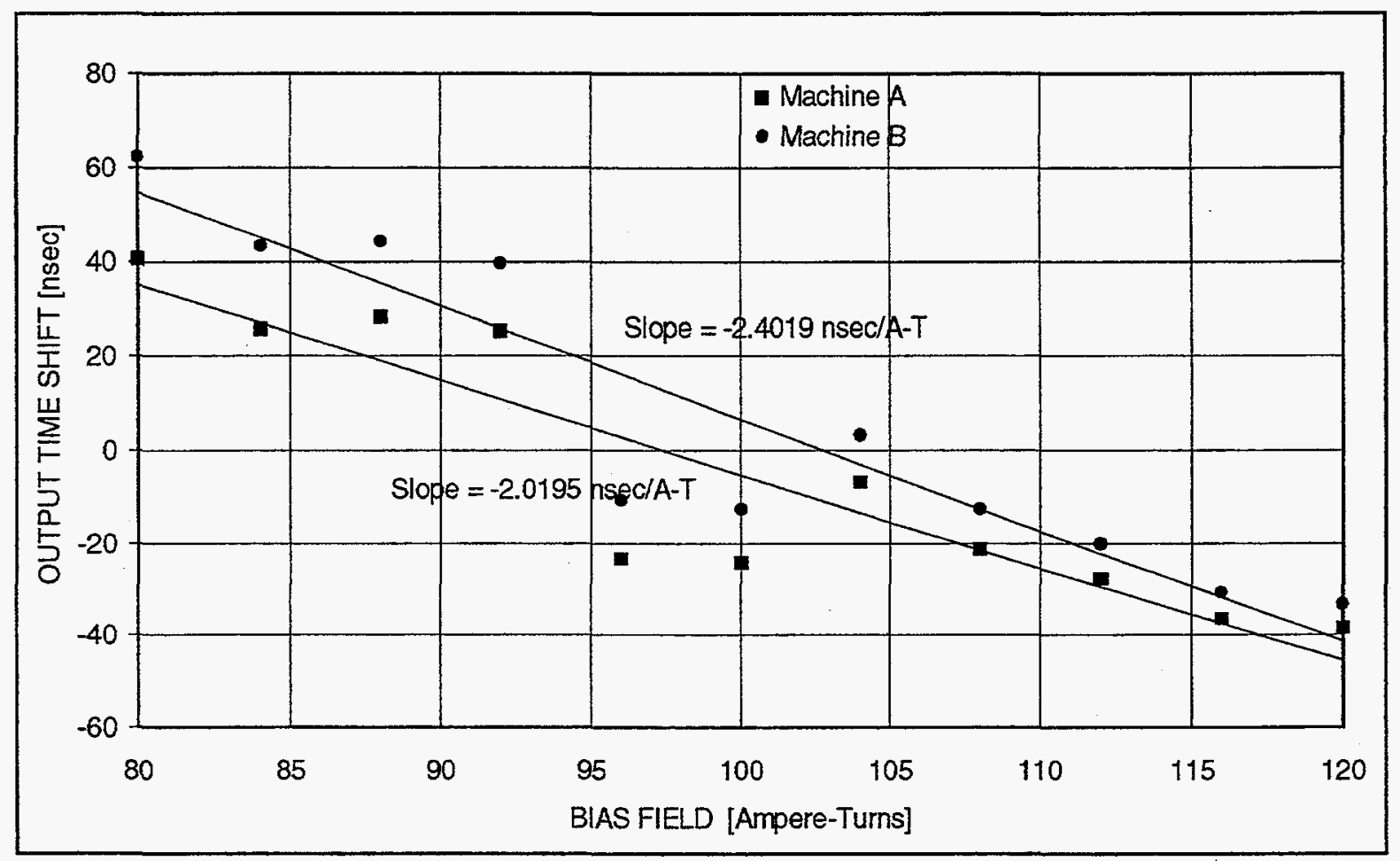

Figure 15. Output time shift on modulator "A" as a function of bias on MS3A and output time shift on modulator "B" as a function of MS3B bias. 
The earlier discussion explained why the nature of the modulator usually causes reflections to be trapped back at the input end of the modulator. Therefore, the slow switches at the input end are most likely to be the source of random shotto-shot timing variations, since any residual energy that is trapped on a magnetic switch affects the switch hold-off time and thus introduces timing variations. Furthermore, the timing variations introduced by a magnetic switch due to trapped residual energy between shots, are proportional to the nominal hold-off time of the switch. That is, the slower switches have the potential to introduce more jitter than the faster switches due to their longer hold-off time. Thus, most of the random shot-to-shot timing variations between a modulator pair will be caused by the slower switches in the early stages of the modulator. As shown in the data presented, these slow switches can be synchronized using magnetic coupling. Since residual energy is not likely to be trapped on the faster switches between shots, they will only introduce static timing offsets at the output of the modulator. These static timing offsets will be a small fraction of the switch hold-off times, so that a mechanism that can correct for a few tens of nanoseconds can be used to compensate for the static timing offsets between the modulators due to the fast switches. With magnetic coupling, trigger timing cannot be used to accomplish this, because the magnetic coupling will prevent the trigger offset from reaching the output of the machines. Calculations indicate that bias control on the fast switches can be used to compensate for the static timing offsets introduced by them. This was tested by varying the bias on MS3A and B with the modulators uncoupled and measuring the time shift in the outputs relative to the trigger pulse, Figure 15. This data shows the necessary tens of nanosecond control range.

\section{Conclusions}

The Dos Lineas modulator pair has been used to demonstrate that it is possible to build a pair of magnetic modulators that have less than $1 \sigma=1 \mathrm{~ns}$ steady-state timing jitter between their outputs, with no special jitter compensation provisions. Attainable jitter is a function of the load. If start-up transients are an issue, they can be compensated using voltage regulation as shown by others or magnetic coupling. Magnetic coupling shows promise as a simple maintenance-free way to control all types of machine-to-machine jitter in magnetic switches and modulators. 


\section{References}

1. R. N. Hitchcock, "Variable Magnetic Switch Design and Control in Repetitive Systems", 1992 20 th Power Modulator Symp., CH3180-7/92/0000-0201, pp. 201-204.

2. M. A. Newton, et al., "Design and Testing of the $5 \mathrm{kHz}, 3 \mathrm{MW}$ Thyratron Modulators for ETA II", 1988 18 th Power Modulator Symp., pp. 71-74.

3. M. A. Newton \& J. A. Watson, "Timing and Voltage Control of Magnetic Modulators on ETA II", 7th IEEE Intl. Pulsed Power Conf., 1989, pp.175-177.

4. J. A. Watson, et al., "Precision Voltage Regulation on the $5 \mathrm{kHz}, 3.125 \mathrm{MW}$ ETA-II Pulsed Power System", 8 ${ }^{\text {th }}$ IEEE Intl. Pulsed Power Conf., 1991, pp. 221-223.

5. M. A. Newton, et.al., "The Power Conditioning System for the Advanced Test Accelerator", 1982 Fifteenth Power Modulator Symp., pp. 333-337.

6. E. G. Cook, et al., "High Average Power Magnetic Modulator for Copper Lasers", 8 ${ }^{\text {th }}$ IEEE Intl. Pulsed Power Conf., 1991, pp.537-542.

7. S. Ashby, et al., "CLIA-A Compact Linear Induction Accelerator System", 8 IEEE Intl. Pulsed Power Conf., 1991, pp. 940-942.

8. Reference Data for Radio Engineers, Howard W. Sams \& Co., Inc., $6^{\text {th }}$ Addition, 1981, pp. 24-27. 


\section{DISTRIBUTION:}

1 MS 1190

1 MS 9300

1 MS 1436

1 MS 1178

1 MS 1194

1 MS 1178

1 MS 1182

1 MS 1193

1 MS 1152

1 MS 1152

1 MS 1152

1 MS 1152

10 MS 1152

1 MS 1152

10 MS 1152

2 MS 1152

1 MS 1152

1 MS 9018

5 MS 0899

2 MS 0619

3 MS 0161

1 MS 0188

1 MS 0188
D. L. Cook, 9500

J. E. Powell, 9300

C. E. Meyers, 4523

R. Hamil, 9512

D. H. McDaniel, 9573

J. J. Ramirez, 9310

B. N. Turman, 9521

G. A. Torres, 9531

J. L. Adcock, 9543

J. J. Flores, 9543

M. J. Harden, 9543

L. E. Martinez, 9543

P. D. Kiekel, 9543

G. E. Pena, 9543

K. W. Reed, 9543

L. X. Schneider, 9543

G. J. Weber, 9543

Central Technical Files, 8940-Z

Technical Library, 4414

Review and Approval Desk, 12690

for DOE/OSTI

Patent and Licensing Office, 11500

Charles Meyer, 4523

Donna Chavez, 4523 